\title{
PRECIOS Y CANTIDADES EN EL COMERCIO ESPAÑOL CON FRANCIA Y GRAN BRETAÑA, 1797-1807: COYUNTURA INTERNACIONAL Y OPCIONES IMPERIALES
}

JAVIER CUENCA ESTEBAN ${ }^{1}$

La historiografía reciente sobre las últimas décadas del Imperio español ha incidido cada vez más sobre aquellos aspectos de la política peninsular que pudieron haber contribuido a la pérdida de las colonias. La primera aportación importante en este campo apareció en la obra de Josep Fontana sobre la quiebra del Antiguo Régimen español en los años 1814-1820. Fontana mostró que la crisis económica de estos años puso al descubierto una contradicción insoluble entre la necesidad de modernizar la hacienda y la imposibilidad de efectuar reformas sustanciales dentro del marco institucional del Estado absoluto. El colapso de las rentas de aduanas y de los caudales de Indias obligó a depender de unos ingresos ordinarios reducidos a la mitad tras la guerra de la Independencia, y cuya insuficiencia no podía subsanarse ya con el agotado crédito público. No es de extrañar que, en estas circunstancias, la recuperación de los ingresos coloniales aplastando los movimientos de secesión se planteara como la única alternativa viable a la modernización de la hacienda. Mientras tanto, los tímidos intentos de reforma fiscal en España fracasaron ante la oposición de los estamentos privilegiados, y el resultado hubo de ser la bancarrota del Estado y un aumento de la presión tributaria sobre el resto del país ${ }^{2}$. El modelo de Fontana, apoyado como estaba en un triple análisis de la coyuntura económica, de la crisis fiscal y de sus mediaciones sociopolíticas, contenía ya los fundamentos para una interpretación global de la actuación española frente a las colonias en un marco temporal mucho más amplio ${ }^{3}$. Una implicación de

1 La recogida de datos para este trabajo fue financiada, en parte, por el Social Sciences and Humanities Researcb Council of Canada. and Humanities Research Council of Canada.
$2 \mathrm{~J}$. Fontana (1971), especialmente pp. $52-69$ y $307-315$. Para una formulación más
reciente de la posición de este autor sobre 12 pérdida de las colonias, véase J. Fontana (1987).

El mismo Fontana extendió las implicaciones de sus análisis al período 1808-1833 3 El mismo Fontana extendió las implicaciones de sus análiosion al contribuciones han aparecido dos
(1973). En sorprendente desconexión con estas y otras los procesos de independencia colo-
libros de menor alcance sobre la reacción española ante los nial: T. Anna (1983) y M. Costeloe (1986). 
este análisis es que, en los críticos años de guerra internacional durante el reinado de Carlos IV, un Estado igualmente incapaz de trascender sus bases sociales en la península hubo de desviar también la presión fiscal hacia las actividades productivas a ambos lados del Atlántico, abortando así la labor del reformismo ilustrado y preparando el terreno para las insurrecciones americanas.

Mientras tanto, la historiografía anglosajona buscaba una explicación del colapso del Imperio en las disrupciones causadas en las colonias por el llamado "nuevo imperialismo" borbónico. Esta línea de interpretación fue vigorosamente articulada por David Brading y por John Lynch, que vieron en las reformas de Carlos III un intento de reintegrar el Imperio en la economía internacional en beneficio de España ${ }^{4}$. La liberalización parcial del comercio de Indias habría estimulado un desarrollo económico que España no podría sustentar, y las medidas fiscales y administrativas cercenaron los privilegios de influyentes instituciones y élites coloniales. El proyecto borbónico chocó a fin de siglo con una serie de circunstancias, unas fortuitas de carácter internacional y otras creadas y agravadas por la política española, cuya dinámica exacerbó el descontento y acabó por crear un vacio de poder en sectores claves del Imperio 5 . La gravedad de la crisis fis. cal de la Corona a partir de 1798 , y el contraste entre la moderación de las medidas desamortizadoras en España y la dureza con que se procedió frente a las colonias y en la imposición sobre el comercio, sugerían ya un cuadro de opciones y motivaciones muy similar al que identificara Fontana durante los reinados de Fernando VII ${ }^{6}$.

La tesis imperialista adquirió su forma más elaborada en un importante artículo de Jacques Barbier, que presentó los problemas fiscales de la Corona a partir de 1796 como un factor determinante de la creciente incoheren. cia de la política colonial española. El modelo de Barbier comparte con el de Fontana el énfasis en la problemática fiscal, pero aquí los factores desencadenantes de la escalada española contra las colonias son las guerras con Francia e Inglaterra durante el reinado de Carlos IV (1793-95, 1796-1802 y

\footnotetext{
4 D. A. Brading (1971), pp. 29-30; J. Lynch (1973), pp. 1-19.

5 La incidencia de estos sucesos en las dependencias americanas varió, naturalmente, con las circunstancias específicas de cada zona. Para una orientación general sobre esta literatura, véanse los ensayos bibliográficos de John Lynch (1971, 2." ed. de 1986), pp. 411-437, y (1989), pp. 436-442. Las obras directamente relevantes para el argumento de este trabajo se citan en la conclusión (sección IV del texto)

6 Véase el intento de síntesis de J. Cuenca Esteban (1978) sobre el período 1765-1826, publicado posteriormente en forma más elaborada (1982). Richard Herr (1989) ha confirmado recientemente sus conocidas conclusiones sobre los límites y cuantía de la desamortización de 1798-1808: pp. 97-98, 133, 143-144, 147-148 y 722-723. La exención de los intereses centrales de la aristocracia española en esta desamortización sigue siendo resaltada en obras generales sobre la época: J. Lynch (1989), pp. 417-418.
} 
1804-1808), y las fuerzas opuestas que mediatizaron la selección de opciones son los intereses del gobierno central y los de la España costera. Barbier identificó el año 1804 como el momento en que las prioridades fiscales de la Corona tomaron precedencia definitivamente sobre los objetivos del reformismo borbónico? ${ }^{7}$. La visión de conjunto que emerge de todas estas contribuciones sitúa la responsabilidad española en una serie de medidas que pudieron haber sacrificado, por una parte, los intereses coloniales a los peninsulares, y por otra los del comercio y la industria española a los de la nobleza y el alto clero.

Con independencia de la muy posible validez de estas hipótesis, la integración de todas ellas en una explicación general de la pérdida de las colonias presenta dificultades cuya gravedad no ha podido escapar a sus proponentes. El juicio sobre la política española ha de basarse, en última instancia, en una valoración de las alternativas históricas disponibles. En defensa de los gobiernos de Carlos IV puede alegarse que heredaron una economía relativamente atrasada cuya reforma no pudo completarse a tiempo, especialmente en el terreno fiscal. Las guerras navales contra Inglaterra fueron quizá un mal menor ante la amenaza latente de invasión francesa ${ }^{8}$. Enfrentados con gastos crecientes y privados temporalmente de ingresos coloniales, los gobiernos españoles hubieron de optar entre medidas de emergencia que habrían acabado enajenando, de una forma u otra, a un amplio espectro de intereses a ambos lados del Atlántico. Es al menos concebible que la adopción de tales medidas hubiera sido inevitable, y sus consecuencias eventualmente irrelevantes debido a la ocupación francesa de la península, a la intervención extranjera en las colonias y a la propia dinámica de los movimientos de independencia. Ante la presencia indiscutible de un cúmulo de circunstancias abrumadoramente adversas a España, la acusación se ve obligada a atrincherarse en una lista de factores contribuyentes de muy diversa índole, y cuya importancia relativa es difícil de valorar sin recurrir a hipótesis contrafactuales de dudosa contrastación empírica.

Uno de los objetivos de este trabajo es llamar la atención sobre ciertos aspectos de la coyuntura económica internacional cuyo impacto sobre el comercio de Indias pudo haber contribuido a provocar la insurrección colonial, con independencia de la actuación española. Se ha señalado en otro lugar que las distorsiones causadas por las guerras napoleónicas estimularon a fin de siglo una sobreproducción mundial de las mercancías de

J. A. Barbier (1980). El mismo autor ha mostrado el poder explicativo de su modelo en una larga serie de importantes artículos, citados todos ellos en el más reciente (1989).

* Sigue siendo una opinión ampliamente compartida que la decisión del Príncipe de la

Paz de declarar la guerra a Inglaterra en 1796 fue un grave error 0 . A. Barbier, 1989. p. 365, y J. Lynch, 1989, pp. 394-395). 
origen colonial9. El colapso resultante de los precios de estos productos apunta ya a un posible factor de descontento entre los productores americanos. La hipótesis de partida aquí adoptada es que el flujo y reflujo de guerra y paz en los años 1797-1808 pudo haber agravado este factor de descontento, al debilitar la posición competitiva de los comerciantes peninsulares en los mercados europeos. Se tratará de demostrar que la irrupción de suministros no españoles en el importante mercado francés, ya por mediación neutral o por vía directa durante la tregua de Amiens (1801-04), deprimió los precios de venta de la oferta española de mercancías coloniales en los años de mayor volumen, al mismo tiempo que la demanda americana pujaba al alza los costes de las manufacturas europeas con destino a las Indias. Una implicación de este análisis es que la misma coyuntura que en Europa forzó a los comerciantes españoles a revender barato y a comprar caro, en las colonias pudo haber reducido los ya deprimidos precios de producción y elevado los de consumo, hasta extremos políticamente insostenibles ante las crecientes oportunidades de competencia extranjera.

La configuración de los precios relativos y de los flujos comerciales en estos años sugiere la presencia de factores causales que debieron operar más allá del marco coyuntural arriba contemplado. El análisis aquí propuesto de estos factores causales se basa en un modelo de equilibrio parcial que, reconociendo en principio la importancia de las vicisitudes políticas y militares de la época, busca una explicación económica de la coyuntura en la estructura y composición del comercio franco-español ${ }^{10}$. El hecho central es que los comerciantes españoles operaban en las colonias en régimen teórico de monopolio, tanto de oferta como de demanda, pero acudían a los mercados europeos en condiciones de libre concurrencia. Estos últimos mercados aportaban manufacturas indispensables para el comercio de Indias, a cambio de mercancías que, en su mayor parte, tenían sustitutos de procedencia no española y cuya demanda era, por consiguiente, elástica. El retraso relativo de la economía peninsular perpetuaba términos desfavorables por el lado de las importaciones de manufacturas, y las precarias condiciones de venta de las mercancías coloniales impedian negociar precios remunerativos en Europa ante la amenaza latente de competencia extranjera. No es sorprendente inferir de las cifras disponibles que el componente de tránsito del comercio exterior español resultara especialmente oneroso

9 J. Cuenca Esteban (1990).

10) Se utiliza aquí heurísticamente el término kestructuran para denotar la doble posición de España como intermediario comercial entre Europa y América y como una economía abierta a los intercambios con el exterior para sus necesidades domésticas. El término acomposición" se refiere a las mercancías objeto de tráfico en cada una de las ramas del comercio, cuya importancia analírica se pone de manifiesto en la sección II del texto. 
en términos de remesas de oro y plata hacia el país galo. La vulnerabilidad de este ramo del comercio contrasta con la relativa robustez del estrictamente peninsular, cuya principal mercancía de exportación, la lana merina, parece haberse mantenido en demanda inelástica hasta bien entrado el siglo XIX. Esta robustez explicaría en parte el creciente poder adquisitivo de las exportaciones españolas tras la definitiva contracción del componente colonial durante la guerra de la Independencia. Desde esta amplia perspectiva, la debilidad del Imperio en su encrucijada decisiva no habría sido enteramente un fracaso político ni, desde luego, una circunstancia fortuita, sino consecuencia en parte de la estructura y composición del comercio español.

En sus aspectos económicos, el argumento arriba enunciado puede resumirse en dos tipos de proposiciones, unas empíricas y otras analíticas. El hecho central a constatar es que el comercio de tránsito español se encontró en la década 1797-1807 ante una coyuntura adversa de precios europeos, y que esta coyuntura adversa tendió a agudizarse precisamente en los años de mayor volumen comercial. El análisis propuesto de esta aparente coincidencia se apoya, a su vez, en dos juegos de factores causales, unos extemos, ligados al flujo y reflujo de guerra y paz en estos años, y otros intermos, inherentes a la estructura y composición del comercio español. Los choques sucesivos sobre la oferta europea de mercancías coloniales, y las condiciones de demanda de las exportaciones e importaciones españolas, explicarían conjuntamente los cambios observados en los precios relativos y su impacto diferencial sobre los componentes colonial y peninsular del comercio español.

La contrastación de estas hipótesis requiere un análisis conjunto de flujos comerciales y precios relativos en los años 1797-1807. La importancia de Francia en el presente argumento, como mercado receptor de mercancías coloniales y como fuente de manufacturas para el Imperio español, aconseja centrar el análisis causal en el comercio exterior con el país galo. Este análisis causal se aborda más adelante en las secciones II y III, sobre la base de las estadísticas oficiales francesas. Para un bosquejo previo de los ciclos y tendencias en la presente sección se han utilizado también las conocidas cifras oficiales británicas, que cubren con detalle comparable el comercio anglo-español en los mismos años. La riqueza y calidad de estas estadísticas ha permitido reconstruir, por agregación de unidades físicas valoradas a precios homologados con tipos de cambio internacional, una aproximación plausible al curso y composición del comercio de España con 
ambos países en los años 1797-1821. Complementan estas cifras comerciales seis índices ponderados de precios franceses $\mathrm{e}$ ingleses por grupos de mercancías exportadas e importadas por España, con base en las medias aritméticas respectivas del período $1798-1820^{11}$.

Los resultados de esta reconstrucción confirman la presencia de condiciones coyunturales adversas a España en la década 1797-1807. El plano superior del gráfico 1 recoge tres índices conjuntos de precios franceses e ingleses, con distinción de exportaciones totales a España e importaciones de mercancías coloniales y peninsulares ${ }^{12}$. Los precios de exportación a España, referentes en su mayor parte a tejidos y otras manufacturas, muestran una suave tendencia deflacionista a lo largo del período ${ }^{13}$. En años anteriores a 1806, sin embargo, la serie registra fuertes tirones al alza muy por encima de la tendencia general. Por su parte, los precios de importaciones procedentes de España fluctuaron en estos años a niveles muy inferiores a la media, en claro contraste con la conocida evolución alcista peculiar a los productos primarios o poco elaborados durante la mayor parte de las guerras napoleónicas.

El impacto desfavorable de los precios relativos se vio agravado en la década 1797-1807 por su tendencia a encarecer las exportaciones a España, y a abaratar las importaciones, en los años de mayor volumen comercial. Las correlaciones en juego se aprecian a simple vista comparando las series de precios ya comentadas con las cantidades correspondientes del comercio franco-británico con España, reproducidas estas últimas en el plano inferior del gráfico 1. Los años de guerra naval 1797-1801 vieron iniciarse una fuerte expansión en las exportaciones francesas a España, que culminaría durante la tregua de Amiens en 1802-04. La evolución al alza de los precios de exportación en esta etapa expansiva contrasta con su posterior moderación en años de masivos suministros ingleses a la península durante la ocupación francesa. Por el lado de las importaciones procedentes de España, las correlaciones de precios y cantidades son más acusadas y de signo inver-

11 Las fuentes y procedimientos de elaboración de todas estas cifras se indican con detalle en el Apéndice.

12 Los componentes francés y británico por subperíodos significativos se presentan por separado en el Apéndice, cuadro 2, junto con otras cifras relevantes para el análisis de las secciones II y III del texto.

13 Significativamente, la tendencia deflacionista es común a las dos series subyacentes de precios franceses e ingleses y es más pronunciada en esta última. La congruencia entre estas dos series plantea cuestiones técnicas cuyo análisis rebasa los límites del presente trabajo. Baste recordar al especialista interesado que la serie francesa se basa en su totalidad en precios de mercado plenamente documentados, mientras que la inglesa incorpora subseries de origen institucional y supuestos sobre la evolución de los precios de los tejidos: cif. J. Cuenca Esteban (1987), pp. 227-228, y L. Prados de la Escosura (1984), pp. 138.139. 


\section{GRAFICO 1}

Francia y Gran Bretaña. Comercio conjunto con España*
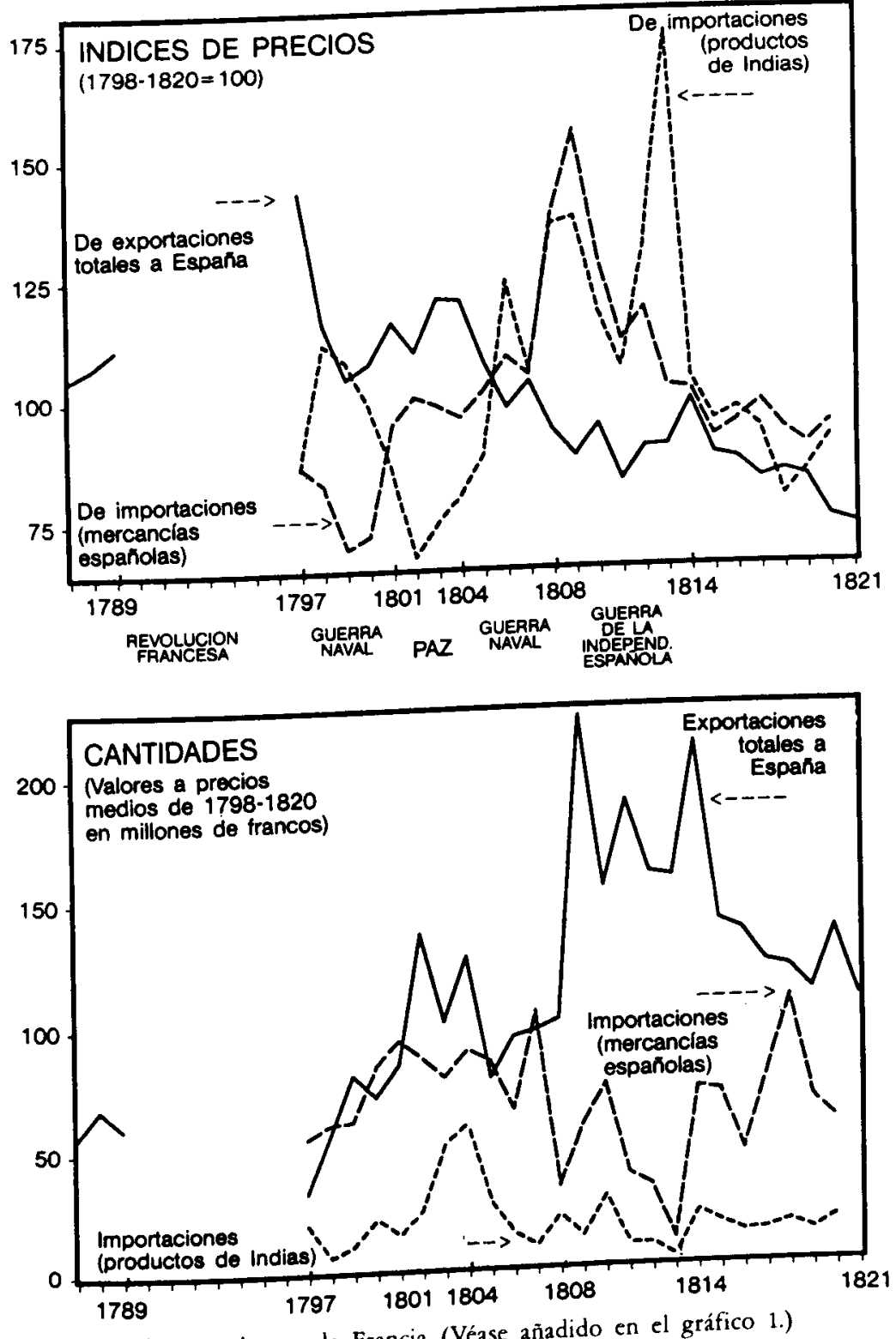

- España e Indias en el caso de Francia. (Véase añadido en el gráfico 1.)

FUENTES Y PROCEDIMIENTOS DE ELABORACIÓN: Véase el Apéndice. 
so. La primera de estas aparentes coincidencias se plasmó a fin de siglo con el colapso de los precios de mercancías españolas en creciente demanda europea. Más significarivo aún, los precios de las mercancías coloniales se hundieron en Francia en los únicos años de abundante oferta española durante la tregua de Amiens. La ruptura o moderación de estas correlaciones adversas a España durante la guerra de la Independencia resalta el carácter distintivo de la coyuntura precedente.

\section{GRAFICO 2}

Francia y Gran Bretaña. Comercio conjunto con España*

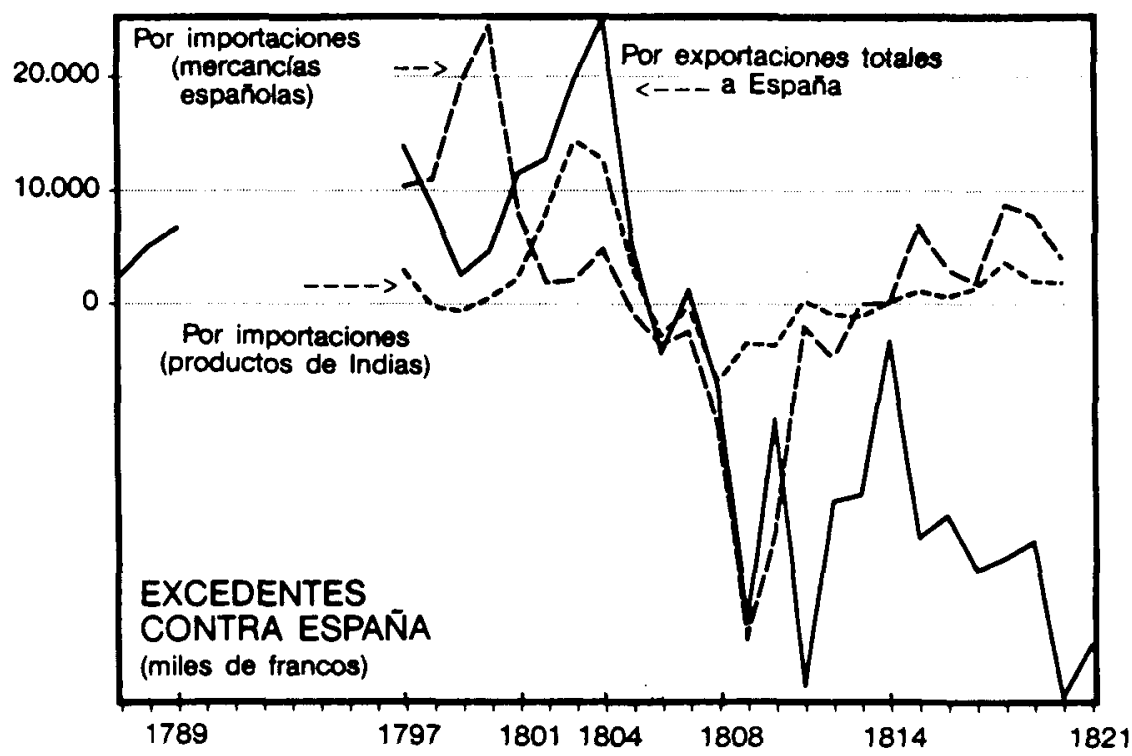

* España e Indias en el caso de Francia.

(Véase añadido en el gráfico 2.)

FUENTES Y PROCEDIMIENTOS DE ELABORACIÓN: Véanse el texto y el Apéndice.

La incidencia de los precios relativos aparece en una tercera perspectiva si se comparan los valores del comercio franco-británico con España, calculados a los precios corrientes de mercado, con los que habrían resultado a los precios medios respectivos del período 1798-1820. Para facilitar la comparación visual de las diferencias en juego por cuenta de exportaciones e 
importaciones, se han calculado en ambos casos los excedentes contra España como saldos positivos. El gráfico 2 recoge en línea continua los excedentes de exportaciones a precios corrientes sobre los mismos valores de exportación calculados a precios constantes, y con trazos discontinuos los excedentes de importaciones calculados a precios constantes sobre los valores corrientes respectivos, con distinción en estos últimos excedentes de importación entre mercancías coloniales y españolas.

Definida en estos términos, la incidencia global de los precios se configura en dos fases de signo opuesto, una favorable al comercio franco-británico con España hasta 1807 y otra desfavorable durante la mayor parte del período posterior. Los críticos años 1797-1805 aparecen claramente diferenciados por la presencia casi continua de excedentes contra España en los tres ramos comerciales indentificados en el gráfico 2. De especial importancia para el presente argumento es la creciente sincronización de los excedentes de exportaciones a España con los de importaciones de mercancías coloniales. La conjunción de los puntos máximos de ambas series durante la tregua de Amiens apunta a un drenaje de divisas en años de fuerte demanda en la península para financiar el renaciente comercio de tránsito. Es quizá en esta última conexión donde una coyuntura internacional ajena a la voluntad española pudo haber comprometido la posición comercial del país en la antesala de la guerra de la Independencia.

\section{II}

El análisis de la coyuntura de 1797-1807 ha identificado circunstancias históricas y mediaciones económicas de potencial relevancia en la explicación de sus causas. En primer lugar, la configuración de los ciclos comerciales a corto plazo acusa el impacto de los conflictos bélicos sobre el tráfico marítimo de las potencias contendientes. En segundo lugar, la confluencia en estos años de excedentes contra España por cuenta de los precios relativos, especialmente en los importantes intercambios franceses de manufacturas por productos de Indias, apunta al comercio franco-español como origen probable de interacciones adversas decisivas ${ }^{14}$. En fin, la culminación de las

iname en los intercambios de manufacturas por productos de Indias donde los voúmes franceses superaron abrumadoramente a los británicos; las importaciones francesas de mercancías peninsulares, por el contrario, fueron muy inferiores a las britanicas: cif. las cifras relevantes del Apéndice, cuadro 2. El predós marcado si se consideran prodo receptor de productos de Indias pudo haber sividarse, a este respecto, que Francia era un bables entradas por vía no española. No deberancías en virtud del tamaño de su población, y

importante mercado terminal para estas mercancias en viministro.
que Inglatera contaba con sus propias fuentes de sumina 
tendencias desfavorables a España precisamente durante la tregua de Amiens apunta, a su vez, al grado de apertura del comercio colonial como posible variable exógena.

Al abordar la explicación formal de las mediaciones causales en juego desde esta triple perspectiva es preciso, ante todo, definir las coordenadas del problema y justificar la selección de criterios entre las opciones disponibles. Las cifras oficiales francesas indican que las exportaciones a España alcanzaron máximos absolutos durante la tregua de Amiens (1801-04), a un promedio muy superior a los registrados en periodos de guerra naval o territorial (1797-1801, 1805-07 y 1808-13). Las diferencias a favor de los años de paz son más marcadas aún en la serie de importaciones totales. Desde una perspectiva dinámica, sin embargo, la influencia de los conflictos bélicos de la época es mucho menos clara. Las tendencias al alza en el comercio franco-español durante la primera guerra con Inglaterra (17971801) contrastan con bruscos descensos en la segunda (1805-07), y las importaciones francesas de mercancías españolas y coloniales tienden a fluctuar en sentido inverso, al igual que los precios respectivos. A un nivel más alto de agregación, ni las balanzas de mercancías ni las remesas españolas de oro y plata muestran correlación estrecha con el flujo y reflujo de guerra y paz $^{15}$. Las razones aparentes de estas discordancias radican, naturalmente, en las complejas interacciones entre cantidades y precios que configuraron las variaciones relativas en los valores corrientes de cada una de las mercancías exportadas e importadas. En última instancia, sin embargo, estas interacciones precisan, a su vez, de una explicación general que, desde un marco de referencia externo al material estadístico, identifique una jerarquía de influencias cuyos efectos predictibles sobre el comercio sean congruentes con la mayoría de las variaciones documentadas.

Los criterios enunciados obligan a descartar aquellas explicaciones cuasi-descriptivas que se limitaran a constatar correlaciones entre flujos comerciales y series afines. Las variantes monocausales de este tipo de explicaciones, como la que buscara una conexión general directa entre las relaciones reales de intercambio y los volúmenes comerciales o la balanza de mercancías, son demostrablemente falsas. Al otro extremo del espectro metodológico, la mera reducción de las fluctuaciones globales a sus determinantes últimos a nivel de mercancías llevaría a conclusiones irrefutables pero tautológicas. Los enfoques intermedios pluricausales son muy útiles a la hora de formular hipótesis, pero resultan insuficientes en ausencia de un

15 Pueden comprobarse estas afirmaciones en los gráficos 3 y 4 (más adelante, en la sección 111 del texto). Véanse también los subtotales relevantes de exportaciones e importaciones francess a precios de mercado en el Apéndice, cuadro 2. 
marco externo de referencia que explique el comportamiento de las variables identificadas como principales.

El marco de referencia aquí adoptado se apoya en un modelo de equilibrio parcial que, reconociendo en principio la importancia de las vicisitudes políticas y militares de la época, busca una explicación económica de la coyuntura en la estructura y composición del comercio franco-español. En este modelo, los sucesivos períodos de guerra y paz alteran un hipotético equilibrio inicial por dos vías distintas, una directa sobre los mercados españoles y otra indirecta sobre la oferta y demanda españolas en Francia. Las cifras disponibles permiten especificar procesos de ajuste a los desequilibrios resultantes en tres submercados franceses distintos, el primero de exportaciones a España y los dos restantes de importaciones de productos de Indias y mercancías españolas ${ }^{16}$. Se examinan los efectos de dos coyunturas progresivamente desfavorables a España: guerra naval, con interrupción total o parcial del comercio de Indias (1797-1801), y navegación directa sin trabas en años de paz (1802-04). El análisis de los procesos de ajuste permite identificar dos variables clave que vinculan las tendencias desfavorables a España ya constatadas con la estructura del comercio: la elasticidad de la demanda francesa de mercancías españolas y de productos de Indias, y el grado de apertura del comercio colonial.

Para facilitar la exposición es útil examinar conjuntamente los efectos de ambas coyunturas, comenzando por el caso más sencillo. El diagrama I resume los procesos de ajuste en el mercado francés de exportaciones a España. La curva de oferta francesa $\left(\mathrm{O}_{\mathrm{F}}\right)$ representa las disponibilidades de venta a España a distintos precios, y la curva de demanda española en trazo continuo $\left(\mathrm{D}_{\mathrm{E}}^{A}\right)$ recoge las preferencias de compra correspondientes. La configuración inicial de estas curvas, y los posteriores desplazamientos de la demanda española, incorporan cifras documentadas e inferencias a confirmar por el análisis de los procesos de ajuste ${ }^{17}$. En un hipotético equilibrio

it El análisis se presenta siempre desde el punto de vista del comercio de Francia con España, para evitar el tratamiento explícito de los intercambios de ambas naciones con las colonias españolas. Las estadísticas oficiales francesas de esta época no distinguen entre el comercio franco-español y los intercambios directos con las colonias españolas. Tampoco es posible identificar las exportaciones francesas a España alli consumione entre España y sus españolas a las Indias, y nos es desconocida la evolución destas lagunas impiden distinguir colonias a nivel de cantidades y valores de mercancias. Estería los intercambios de manuempíricamente entre un "comercio colonal, qué de España, y un "comercio europeon, que facturas francesas por productos de Indias a dencia y destino domésticos. abarcaría las restantes mercancías de procedentos indicados de la demanda española en el

17 Se ha comprobado que los desplazamientó de las variaciones documentadas, sin apemercado francés explican por sí mismorta francesa. nas postular cambio alguno en la oferta francesa. 


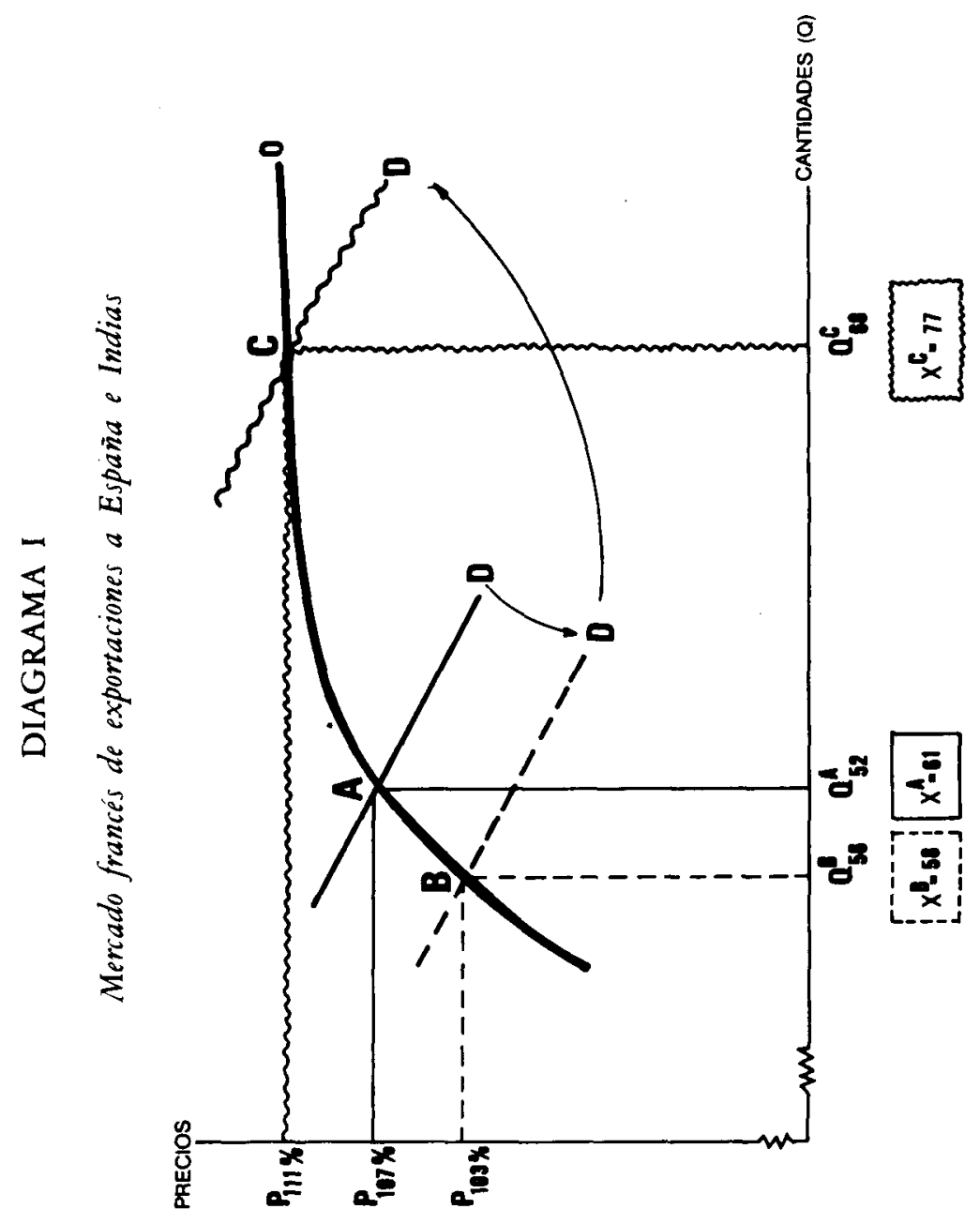

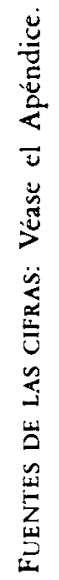


inicial definido por las medias aritméticas del período 1797-1808, la confluencia de la oferta francesa $\left(\mathrm{O}_{\mathrm{F}}\right)$ y la demanda española $\left(\mathrm{D}_{\mathrm{E}}^{A}\right)$ en el punto A determina la cantidad o volumen de exportaciones francesas a España en 58 millones de francos (eje horizontal: $Q_{88}^{\Lambda}$ ), el precio corresfrancos (rectángulo definido por el punto $\left.A: Q_{s 8}^{\Lambda} \cdot P_{107 \%}^{\Lambda}=X_{61}^{A}\right)^{18}$.

La guerra naval de 1797-1801 dificulta seriamente el tráfico atlántico, con la consiguiente contracción de la demanda española de mercancías francesas con destino a las colonias. Siempre con referencia al diagrama $\mathrm{I}$, el comienzo de las hostilidades con la marina inglesa desencadena un proceso de ajuste desde el punto $A$ hasta el punto $B$, definido este último por las medias aritméticas de los años de guerra 1798-1801 ${ }^{19}$. La demanda española en el mercado francés ( $D_{\mathrm{E}}^{A}$ ) se desplaza hacia la izquierda, hasta la posición indicada con trazos discontinuos $\left(\mathrm{D}_{\mathrm{E}}^{\mathrm{B}}\right)$. En el nuevo equilibrio (punto B), la cantidad exportada a España y el precio correspondiente $\left(Q_{36}^{\mathrm{B}}\right.$ y $\left.\mathrm{P}_{104 \%}^{\mathrm{B}}\right)$ son ambos inferiores a la media del período de referencia (1797-1808: $\mathrm{Q}_{58}^{\mathrm{A}}$ y $\left.\mathrm{P}_{107 \%}^{\mathrm{A}}\right)$, con la consiguiente reducción en el valor corriente de las exportaciones (hasta $\mathrm{X}_{58}^{\mathrm{B}}$ : rectángulo definido por el punto $\mathrm{B})^{20}$.

La tregua de Amiens (1801-1804) permite reanudar el comercio colonial, con efectos expansivos sobre la demanda española de mercancías francesas. Esta nueva situación se representa en el diagrama I como un proceso de ajuste desde el punto B (coyuntura de guerra de 1798-1801) hasta el punto $C$, definido este último por las medias aritméticas de los años de paz 1802-180421. La demanda española ( $D_{\mathrm{E}}^{\mathrm{B}}$. línea discontinua) se desplaza hacia la derecha hasta la posición indicada con trazos irregulares $\left(D_{\mathrm{E}}^{\mathrm{C}}\right)$. En el nuevo equilibrio (punto $\mathrm{C}$ ), la cantidad exportada y el precio correspondiente $\left(Q_{68}^{C}\right.$ y $\left.P_{112 \%}^{C}\right)$ son ambos superiores a las medias del período de referencia (1797-1808: $\mathrm{Q}_{s 8}^{\mathrm{A}}$ y $\left.\mathrm{P}_{107 \%}^{\mathrm{A}}\right)$, con el consiguiente aumento en el valor corriente de las ventas a España (hasta $\mathrm{X}_{77}^{\mathrm{C}}$ : rectángulo definido por el punto C) $^{22}$.

andicadas con subindices corresponden a las medias aritméticas documentadas del período 1797-1808: fuentes y datos en el Apéndice, cuadro 2.

19 No es posible ajustar este análisis a los altibajos del comercio de Indias, por falta de datos mensuales en las estadísticas francesas. El año 1797 encaja de lleno en la coyuntura de guerra naval, pero la ausencia de datos fidedignos de precios franceses con anterioridad a 1798 aconseja excluir su tratamiento explícito.

201 Es del todo concebible que la contracción de la demanda porque muchas de aquéllas compelas mercancías francesas para consumo en la peninsula, porabido a la guerra.

tían con manufacturas españolas en relativa abundas del cese de hostilidades en cada caso,

21 No es posible ajustar este análisis a las fechas del

por falta de datos mensuales en las estadisticas fodo concebible que la expansión de la

22 Aquí, como en los años 1797-1801, cs del todo concebible que la expansión de la 
El diagrama I pone de relieve la posición de España como país comprador en el mercado francés. Se observa a simple vista que las tres variables de cantidad, precio y valor evolucionan todas en el mismo sentido. En condiciones de guerra naval, España compra menos y más barato a un coste inferior (posición B). En años de paz aumentan las compras a Francia a precios en moderado ascenso, pero a costes crecientes en proporción a la cantidad comprada (posición C) ${ }^{23}$. Las implicaciones de la evolución de los costes se examinan en la sección III del texto, en relación con la balanza de comercio y las remesas españolas de oro y plata. Lo que interesa destacar aquí es que los precios de compra en Francia aumentaron precisamente en los años de mayor volumen comercial, durante la tregua de Amiens, con consecuencias potencialmente adversas sobre las reventas españolas en los mercados coloniales.

La evaluación global de la posición española requiere un análisis más complejo del papel de Francia como país comprador de mercancías españo. las y coloniales. La primera coyuntura a considerar desde esta perspectiva, la guerra naval de 1797-1801, desequilibra indirectamente los mercados franceses de importación a través de su impacto diferencial sobre la oferta española. En la península, la contracción del comercio colonial altera drásticamente la composición de excedentes exportables, con inmediata escasez de productos de Indias y relativa abundancia de mercancías europeas y españolas sin salida para las colonias ${ }^{24}$.

demanda española afectara también a las mercancías francesas para consumo en la península, porque aquéllas competían con manufacturas españolas en relativa escasez debido a la apertura de las comunicaciones atlánticas.

23 Puede comprobarse esta última observación comparando los subíndices numéricos de

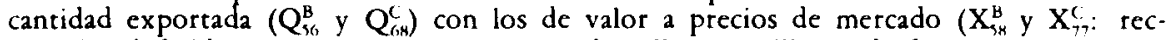
tángulos definidos por los puntos $\mathrm{B}$ y $\mathrm{C}$ ), todos ellos en millones de francos. La creciente moderación en el aumento de los precios se debe a la configuración elástica de la oferta francesa $\left(\mathrm{O}_{\mathrm{F}}\right)$, que, como es sabido, es característica de los productos manufacturados.

24 En sus efectos sobre los mercados españoles, la coyuntura de guerra naval consta, en realidad, de tres fases distintas. Los prolongados bloqueos de Cádiz y Barcelona tras la declaración de guerra a Inglaterra (5 de octubre de 1796) llegaron a interrumpir casi por completo las comunicaciones atlánticas en 1797, con la consiguiente disrupción del comercio de tránsito por la península. Con la autorización del comercio neutral, el 18 de noviem. bre de 1797, se inició una incipiente recuperación, pero hay razones para pensar que el valor de este comercio fue inferior al de los intercambios directos con las colonias en tiempo de paz. Lo mismo puede decirse del tráfico de licencias que permitió España tras la suspensión del comercio de neutrales, el 20 de abril de 1799 . En lo que se refiere al comercio directo por puertos españoles, las cuentas mensuales del derecho de averia reflejan fielmente la marcha de la guerra y las veleidades de la política española. Fuentes y análisis en J. Cuenca Esteban (1981), passim. 


\section{DIAGRAMA II}

Mercado francés de importaciones de productos de Indias

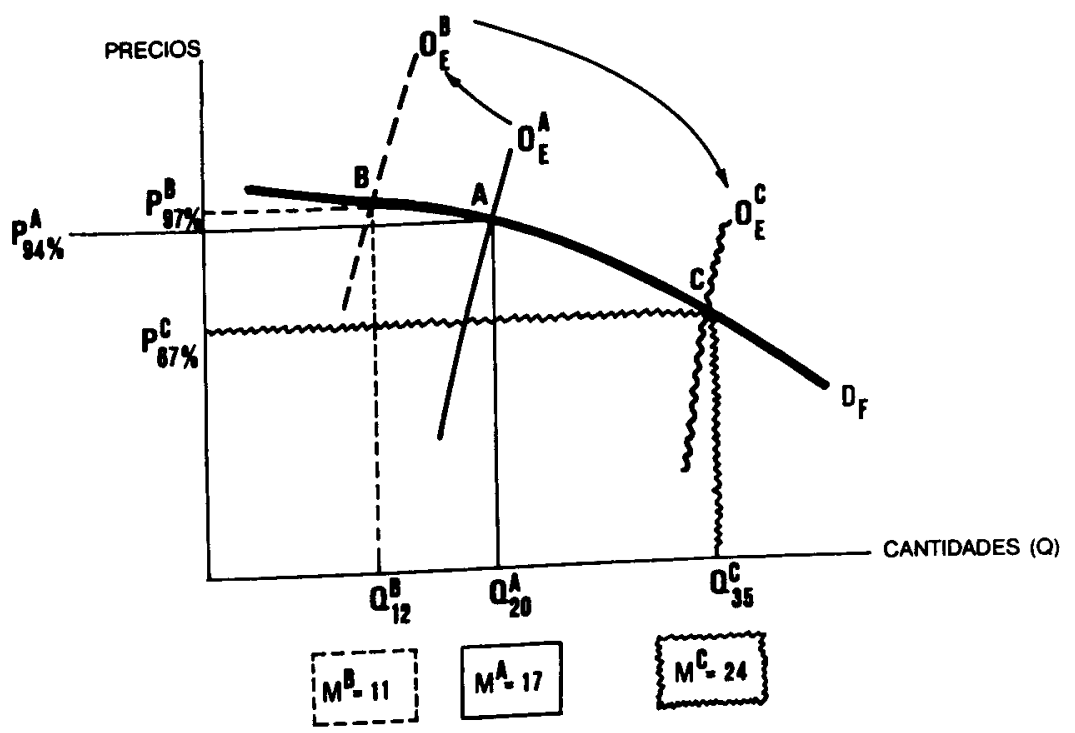

FueNTES DE LAS Cifras: Véase el Apéndice.

La incidencia en Francia de la escasez de productos de Indias se ilustra en el diagrama II como un proceso de ajuste desde el punto A hasta el punto $\mathrm{B}$, definido este último por las medias aritméticas de los años de guerra 1798-180125. La oferta española de mercancías coloniales $\left(\mathrm{O}_{\mathrm{E}}^{A}\right)$ se desplaza hacia la izquierda hasta el nivel $\mathrm{O}_{\mathrm{E}}^{\mathrm{B}}$, con la consiguiente contracción de las importaciones francesas (eje horizontal: $Q_{12}^{B}$ ) a precios ligeramente superiores (eje vertical: $\mathrm{P}_{97 \%}^{\mathrm{B}}$ ).

Las interacciones descritas en el diagrama II revelan un primer vínculo causal entre la composición del comercio y las tendencias desfavorables a España. Con referencia a los puntos de equilibrio A y B, se observa que un modesto encarecimiento de las mercancías de Indias (eje vertical) ha reducido el volumen importado por Francia en proporción muy superior (eje

25 Se recuerda al lector que no es posible ajustar este análisis a los altibajos del comercio de Indias, por falta de datos mensuales en las estadísticas francesas. El año 1797 encaja de lleno en la coyuntura de guerra naval, pero la ausencia de datos fidedignos de precios franceses con anterioridad a 1798 aconseja excluir su tratamiento explícito. 
horizontal) ${ }^{2 \hbar}$. Las magnitudes en juego confirman que la demanda francesa de productos de Indias era elástica, en el sentido de que las cantidades importadas respondían más que proporcionalmente a los cambios de pre$\operatorname{cios}^{27}$. La implicación más general de esta notable elasticidad de respuesta es que los comerciantes peninsulares no podían elevar impunemente sus precios de exportación, porque los productos de Indias competían en Francia con sustitutos prácticamente idénticos de procedencia no española. En las circunstancias concretas de guerra naval aquí consideradas, no es sorprendente comprobar que la inevitable reducción de la oferta española de mercancías coloniales no lograra crear en Francia la escasez necesaria para forzar un alza comparable en sus precios.

\section{DIAGRAMA III}

Mercado francés de importaciones de mercancias españolas

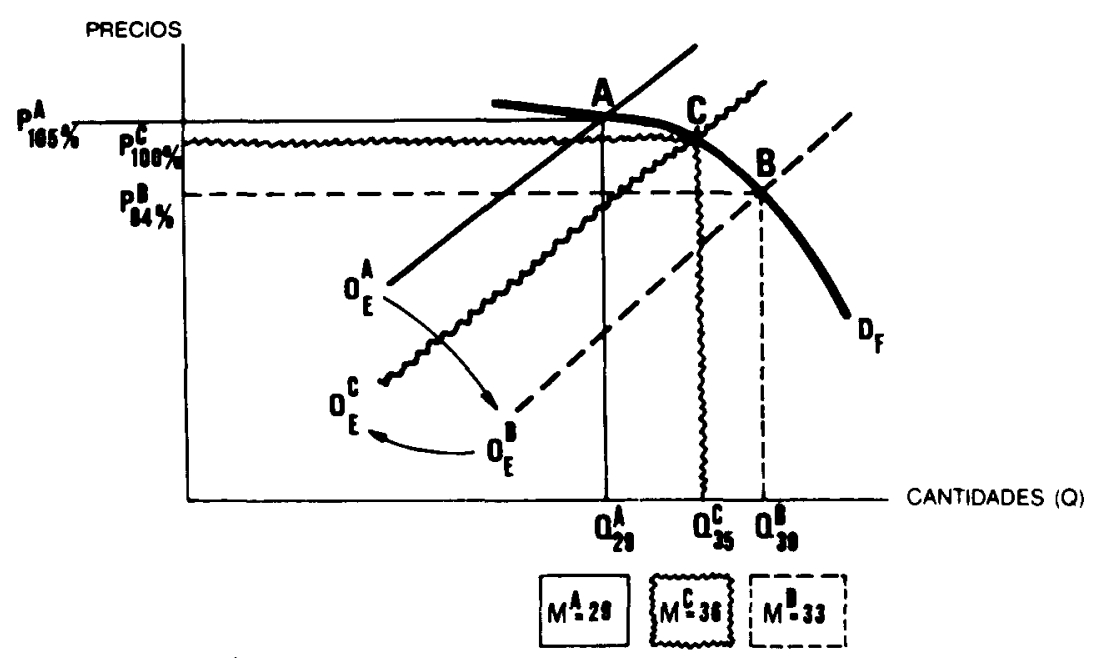

FUENTES DE LAS CIFRAS: Véase el Apéndice.

${ }^{26}$ En un 40 por 100 (de 20 a 12 millones de francos a precios constantes). Las variaciones relativas resultan aquí exageradas por la elección del período de partida (1797-1808: punto A) y por su referencia a las medias aritméticas de los turbulentos años 1798-1801 (punto B).

27 En general, la mayoría de las cifras anuales son congruentes con fluctuaciones de la oferta española de productos de Indias en la sección elástica o tramo superior de la curva de demanda francesa. Puede comprobarse a simple vista que un encarecimiento de la misma magnitud en la sección inelástica de la curva de demanda (punto $\mathrm{C}$ en el tramo derecho) habría reducido el volumen importado en proporción muy inferior al alza de precio, en clara contradicción con las variaciones documentadas del período 1798-1801. Las regresiones efectuadas de cantidades sobre precios sitúan significativamente la elasticidad de esta demanda por encima de $-1,5$ en los períodos $1798-1820$ y $1797-1808$. 
A agravar los efectos de la coyuntura de guerra contribuyó el colapso de los precios de importantes mercancias españolas en el mercado francés correspondiente. La incidencia de la guerra en este mercado se representa en el diagrama III como un proceso de ajuste desde el punto A hasta el punto B. Aquí el papel protagonista corresponde a las mercancías españolas sin salida para las colonias, cuya oferta en expansión en el mercado francés (desde $\mathrm{O}_{\mathrm{E}}^{\mathrm{A}}$ hasta $\mathrm{O}_{\mathrm{E}}^{\mathrm{B}}$ ) precipita un fuerte aumento en las compras a España a precios muy inferiores.

Las interacciones en juego en el submercado francés de mercancías españolas delatan también la presencia de factores adversos a España, tanto en la península como en el país galo. Por el lado de la oferta española, la contracción del tráfico de Indias hubo de forzar condiciones de relativa abundancia en dos grupos de mercancías de origen peninsular: las fibras textiles sin empleo en la industria española de exportación, y ciertos productos agrícolas sin salida para las colonias ${ }^{28}$. En el caso de las fibras textiles, el consiguiente colapso de los precios en el mercado francés se explica, en parte, por la presión de la oferta española sobre un sector manufacturero deprimido en su demanda de materias primas por la pérdida de sus propios mercados coloniales ${ }^{29}$.

Aquí como en todas partes, la magnitud de respuesta en los precios requiere, a su vez, una explicación por el lado de la demanda francesa. Siempre con referencia a los puntos A y B en el diagrama III, se observa que el crecimiento en volumen de las importaciones francesas de productos espanoles (eje horizontal) apenas supera en términos porcentuales a la disminución de los precios (eje vertical). En contraste con la modesta apreciación de los productos de Indias en los mismos años (diagrama II), la superior flexibilidad a la baja de los precios de los españoles apunta al considerable

28 Así se infiere de las series individuales de precios franceses ya documentadas. Entre fuertes presiones deflacionistas en Francia durante estos años destaa lana merina, el aguardiente y el algodón. Se ha comprobado que can por su importancia la lana merina, cl agua las mismas mercancías tendieron a fluctuar en los precios españoles, ingleses y holandeses de las mismas m. Llopis Agelán (1982), pp. 82-83: forma parecida: series elaboradas y datos primaros y A. Schwartz (1953), Supplement in Microlana española; A. D. Gayer, W. W. Rostow y A. J. Schwast (1946 y 1964), vol. I, pp. 276 film, p. 663: "Brandy, Cognac in bond"; N. W. Posthume España y de sus Indias (1792-1808), 279: lana española en Amsterdam; Correo menante Corredores de Cádiz, 1803-1820, Archivo passim, y Libros de precios corrientes de la Lonja de Come 1131 y 1134: "aguardiente prueba de aceyte".

General de Indias, Consulados, libros 1131 de Inglaterra contra Francia y España sobre la industria

29 Los efectos de la guerra naval de Inglaterra contra Fil como desplazamientos hacia la francesa podrian representarse en los diagramas II y lll con de importaciones. Se han izquierda de las curvas de demanda francesa en por su escaso poder explicativo en comparaomitido estos efectos en el argumento central por ha indicado, los desplazación con las fluctuaciones de las ofertas españolas. Como de las variaciones documentadas. mientos en estas últimas explican por sí mismos la mayoría de las variaciones documentadas. 
peso específico entre estos últimos de la todavía insustituible lana merina, cuya demanda en Francia era menos elástica que la de otras mercancías ${ }^{30}$. En ambos casos, las condiciones de venta en el mercado francés mediatizaron la incidencia de los excedentes exportables en la península, con consecuencias desfavorables a España.

La apertura del tráfico atlántico durante la tregua de Amiens (18011804) alteró, una vez más, la composición de los excedentes exportables en la península, con inmediata escasez de mercancías europeas en demanda colonial y con eventual abundancia de productos de Indias. Las consecuencias del cese de hostilidades se representan en los diagramas II y III como procesos de ajuste desde el punto B (coyuntura de guerra de 1798-1801) hasta el punto $C$, definido este último en cada caso por las medias aritméticas de los años de paz 1802-1804 ${ }^{31}$. En el mercado francés de productos de Indias (diagrama II) aumenta la oferta española hacia el nivel $\mathrm{O}_{\mathrm{E}}^{C}$, pero la expansión resultante en las importaciones francesas abarata sus precios. Lo contrario se aplica a las mercancias españolas en demanda colonial, cuya oferta en contracción en el mercado francés correspondiente (diagrama III: desde $O_{\mathrm{E}}^{\mathrm{B}}$ hasta $\mathrm{O}_{\mathrm{E}}^{\mathrm{C}}$ ) reduce las compras a España a precios moderadamente superiores.

En su impacto diferencial sobre los precios y cantidades de las importaciones francesas, la tregua de Amiens invirtió la dirección de los cambios sin alterar para España el signo adverso de la coyuntura. En contraste con lo sucedido en los años 1798-1801, fueron los productos de Indias, y no los peninsulares, los que se hallaron ahora en relativa abundancia, y aquí la oferta española afluyó al mercado francés en proporciones masivas y a precios aún más deprimidos ${ }^{32}$. La gestación de esta nueva calamidad se remonta a los últimos años de la guerra naval de 1797-1801, durante los cuales habían ganado terreno las importaciones francesas de mercancías coloniales

30 Las medias aritméticas para los años 1798-1801 son congruentes con un desplazamiento de la oferta española desde la sección elástica de la demanda francesa (punto A en el diagrama III) hasta la sección inelástica (punto B). Puede comprobarse a simple vista que un desplazamiento similar dentro de la sección elástica (desde el extremo izquierdo de la curva de demanda hasta el punto A) implicaría una disminución de los precios proporcionalmente muy inferior al crecimiento en volumen de las importaciones, en clata contradicción con las variaciones documentadas.

31 No es posible ajustar este análisis a las fechas del cese de hostilidades en cada caso, por falta de datos mensuales en las estadisticas francesas.

32 Véase el gráfico 4 (más adelante, en la sección III del texto: planos superior e intermedio). En Cádiz, los precios de las principales mercancías coloniales reexportadas a Francia en 1802-1804 (añil y azúcar) se mantuvieron muy deprimidos en estos años: medias anuales en J. Cuenca Esteban (1990), p. 391. 
por vía no española ${ }^{33}$. A engrosar estos suministros contribuyó, tal vez, la suspensión del comercio neutral por parte de España el 20 de abril de 1799, que parece haber convertido a Holanda y a Hamburgo en los principales clientes de los Estados Unidos en este ramo del comercio de tránsito ${ }^{34}$. En todo caso, los elevadísimos precios en Cádiz de los productos de Indias en demanda elástica pudieron haber acentuado en Francia la sustitución de importaciones por mediación neutral ${ }^{35}$.

Mientras tanto, el inminente retorno de la paz auguraba condiciones de sobreabundancia en la península. Hasta 1802 continuaron despachándose para España importantes partidas estadounidenses de azúcar y café, y en este año arribaron en Cádiz cantidades sin precedentes de mercancías de Indias, retenidas en parte en los puertos de origen durante la guerra ${ }^{36}$. El consiguiente hundimiento de los precios en Cádiz se prolongó, en la mayoría de los casos, hasta 1804, el año de mayores reexportaciones a Francia $^{37}$. Mejor suerte corrieron las mercancías de origen peninsular en demanda inelástica, cuyos precios en Francia reaccionaron al alza más que proporcionalmente a la escasez creada por la expansión de las exportaciones espanolas a América ${ }^{38}$. Pero esa misma expansión del tráfico colonial encareció

33 De 63 y 68 millones de francos en 1798 y 1799 a más de 100 millones anuales en los tres años 1800-02; los suministros holandeses de mercancías coloniales superaron, con mucho, a los de procedencia española en todos estos años: cifras oficiales francesas, en Tableaux imprimés des importations et exportations, ANP (Archives Nationales de Paris), F 12, Carton 251, passim. Véanse, también, las medias aritméticas relevantes en el Apéndice, cuadro 2 (importaciones francesas de productos coloniales, resto del mundo y Holanda). La importancia relativa de las importaciones francesas de "España y sus colonias", "Holanda y sus colonias" y "Alemania" en estos años puede apreciarse en J. Cuenca Esteban (1987), p. 228, gráfico 1 (plano intermedio).

34 Así se infiere de las cifras oficiales norreamericanas de estos años: véase T. Pitkin (1835), pp. 157, 159 y 161 (azúcar y café por países de destino a partir de 1800). Para otros años y mercancías es preciso consultar la fuente original: American State Papers [U. S. Congress] $(1832,1834)$ : Class 4, "Commerce and Navigation". vol. I, passim.

5 Para una visión comparada de los precios relativos de seis mercancías coloniales en los Estados Unidos en 1798-1800, véase J. Cuenca Esteban Cifico 12.1 (medias anuales en pp. 391 y 393-396).

36 Cifras en T. Pitkin (1835), pp. 157, 159 y 161 (exportaciones estadounidenses a España a partir de 1800), y en A. García-Baquero González (1972), pp. 165, 170 y 174́: cantidades de importación en Cádiz, 1802-1804.

37 Medias anuales de precios corrientes en Cádiz en J. Cuenca Esteban (1990), p. 391 La producción de añil en Guatemala acusó el impacto de una plaga de langostas que destru. yó las cosechas de 1802 y 1803 (M. L. Wortman, 1982, p. 185), pero en noviembre de 1803 seguía habiendo abundantes existencias en Cádiz: R. S. Smith (1959), p. 203. Otras mercany sequías en estos años eran de escasa importancia en el comercio y tabaco en la futura Venezuela: P. M. McKinley, 1985, pp. 139-140). La producconol (cacao yrana en Nueva España continuó aumentando hasta 1803, en condiciones locales de fuerte demanda y precios ascendientes: cifras y análisis en B. R. Hamnett (1971) PP. 170 y $114-115$

* Véasc el diagrama III (cantidades y precios correspondientes a los puntos B y C). 
también las manufacturas europeas con destino a las Indias ${ }^{39}$, reforzando así los efectos adversos del colapso de los precios de venta en Francia sobre el comercio de tránsito español.

La segunda guerra naval con Inglaterta (1804-08) parece haber reproducido con diferencias significativas las condiciones coyunturales de la primera (1797-1801) ${ }^{40}$. Los años 1805-08 vieron fuertes descensos en los tres ramos del comercio franco-español, especialmente en los valores corrientes de las exportaciones a España y en las importaciones francesas de mercancías de Indias. La disminución de estas últimas a precios muy elevados es congruente con una brusca contracción de la oferta española, debida, a su vez, a la interrupción de los suministros de América ${ }^{41}$. También es explicable el anómalo descenso en las importaciones francesas de mercancías espanolas ${ }^{42}$, en este caso porque la mayor parte de la lana merina fue acaparada por Inglaterra en los años 1805-0743.

Más difícil de interpretar es la estabilidad del valor-promedio de cantidades exportadas a España al mismo nivel que en los años 1802-04, y a pre-

A precios más altos, naturalmente, la demanda de mercancías espanolas se torna elástica en virtud del carácter sustirutivo de la producción francesa.

39 Véanse los índices de precios en el plano inferior del gráfico 4, que se presenta a continuación en la sección III. Las medias aritméticas del periodo 1802-04 (Apéndice, cuadro 2) no permiten apreciar la tendencia alcista de los precios franceses de exportación en estos años.

40 Como referencia para el análisis de la coyuntura de 1805-08, deben consultarse con cautela el gráfico 4 (comercio franco-español: sección III del texto), el gráfico l (comercio franco-británico con España: sección I) y las medias aritméticas facilitadas en el Apéndice (cuadro 2). Las estadísticas oficiales francesas asignan a 1806 parte de los valores de 1805 , y no indican la procedencia española o colonial de importantes partidas de algodón en 1805 y en 1808: véanse el Apéndice (segundo párrafo) y la nota del cuadro 1. Tampoco son plenamente comparables los ciclos de 1805-08 con los de 1797-1801, por falta de cifras anteriores a 1797. Aquí, como en todas partes, la dificultad insoslayable es la ausencia de cifras mensuales del comercio francés, que impide ajustar el análisis a los puntos de inflexión en la arena política internacional.

41 En los términos ya comentados del diagrama II, y con referencia a los promedios no incorporados del período 1805-07 (cifras en el Apéndice, cuadro 2), la oferta española $\left(\mathrm{O}_{\mathrm{E}}^{\mathrm{C}}\right)$ se desplaza hacia la izquierda hasta un lugar intermedio entre los puntos $\mathrm{A}$ y $\mathrm{B}$. Los promedios de 1805-07 sugieren también un desplazamiento hacia la derecha de la demanda francesa de productos de Indias $\left(D_{F}\right)$, debido quizá a un encarecimiento relativo de los suministros por vía no española. Aquí, como en el mercado francés de exportaciones a España, la complejidad de este período obligaría a relajar el supuesto de que la oferta y la demanda francesas $\left(\mathrm{O}_{\mathrm{F}}\right.$ y $\left.\mathrm{D}_{\mathrm{F}}\right)$ permanecieron constantes.

42 Descenso anómalo en el sentido de que es opuesto a lo sucedido durante la primera guerra naval. Recuérdese que el diagrama III no incorpora las cifras comerciales británicas.

43 Son estas compras de lana a España las que explican, en gran parte, las infladas cifras de importaciones británicas en estos años: cif. los promedios de este ramo del comercio en el Apéndice, cuadro 2. 
cios muy inferiores ${ }^{44}$. Es de suponer que la disrupción del comercio colonial a partir de 1805 hubiera creado condiciones de abundancia de manufacturas en la península, con la consiguiente contracción de la demanda española en el mercado francés. La hipótesis más compatible con los elevados volúmenes de venta a España en estos años es una reducción simultánea en los costos relativos de la industria francesa ${ }^{45}$. Desde el punto de vista de España, el sostenido auge en las importaciones de manufacturas francesas parece haber coincidido con una incipiente modernización de la industria algodonera catalana entre 1802 y 1807, dirigida ya en buena parte hacia los mercados domésticos ${ }^{46}$. Sin perjuicio de que pueda justificarse una visión más optimista desde otras perspectivas, la evolución del comercio exterior en estos años apunta a un deterioro de la capacidad competitiva del país en la antesala misma de la guerra de la Independencia.

\section{III}

Desde el punto de vista de la balanza de pagos, el rasgo más saliente de la década 1797-1807 es la notable afluencia de remesas españolas de oro y plata hacia el país galo durante los años $1803-05^{47}$. La importancia de estas remesas radica tanto en su magnitud como en su acusada desproporción con los saldos de la balanza francesa de mercancías, según se aprecia en el gráfico 3. Las magnitudes en juego podrían explicarse, en parte, por la llegada de fondos retenidos en América durante la guerra naval de 1797-1801, pero un drenaje similar de divisas españolas se había producido ya en los años 1787-89 en circunstancias muy distintas. Tampoco son plenamente atribuibles estos flujos de dinero a simples pagos en cobertura de los saldos comerciales contra España, porque el endeudamiento implícito en la balanza francesa de mercancías fue muy inferior a los envíos españoles de oro y

44 Cifras en el Apéndice, cuadro 2. Se utilizan aquí los promedios de 1805-07 para excluir distorsiones causadas por el comienzo de la guerra de la Independencia en 1808.

45 En los términos ya comentados del diagrama I, los promedios de exportación para 1805-07 sitúan el nuevo equilibrio de guerra muy por debajo del punto $C$ (coyuntura de paz, 1802-04), en la línea vertical irregular hacia el eje de abscisas (cifras en el Apéndice, cuadro 2). Este nuevo equilibrio es compatible con un doble desplazamiento a partir del punto $C$ : uno hacia la izquierda en la curva de demanda española $\left(D_{E}\right)$, debido a la guerra abajo en la curva de oferta francesa $\left(\mathrm{O}_{\mathrm{F}}\right)$, debido a la reducción de los costes.

46 Sobre este último extremo, véase J. Nadal (1975), pp. 189-192.

47 Las estadísticas oficiales francesas se limitan a indicar la naturaleza de las obligaciones que sas de oro y plata por países de origen, sin especificar la naturaleza de las obligaciones que motivaron estos pagos. 
plata en 1803-1805 y se mantuvo muy por encima en 1811-19. En todo caso, la profusión de remesas de los años 1803-05 constituye una clara excepción a la norma general del período 1797-1821, y por ello ha de buscarse una explicación de sus causas en condiciones peculiares a la coyuntura de la tregua de Amiens.

\section{GRAFICO 3}

Francia. Comercio con España e Indias

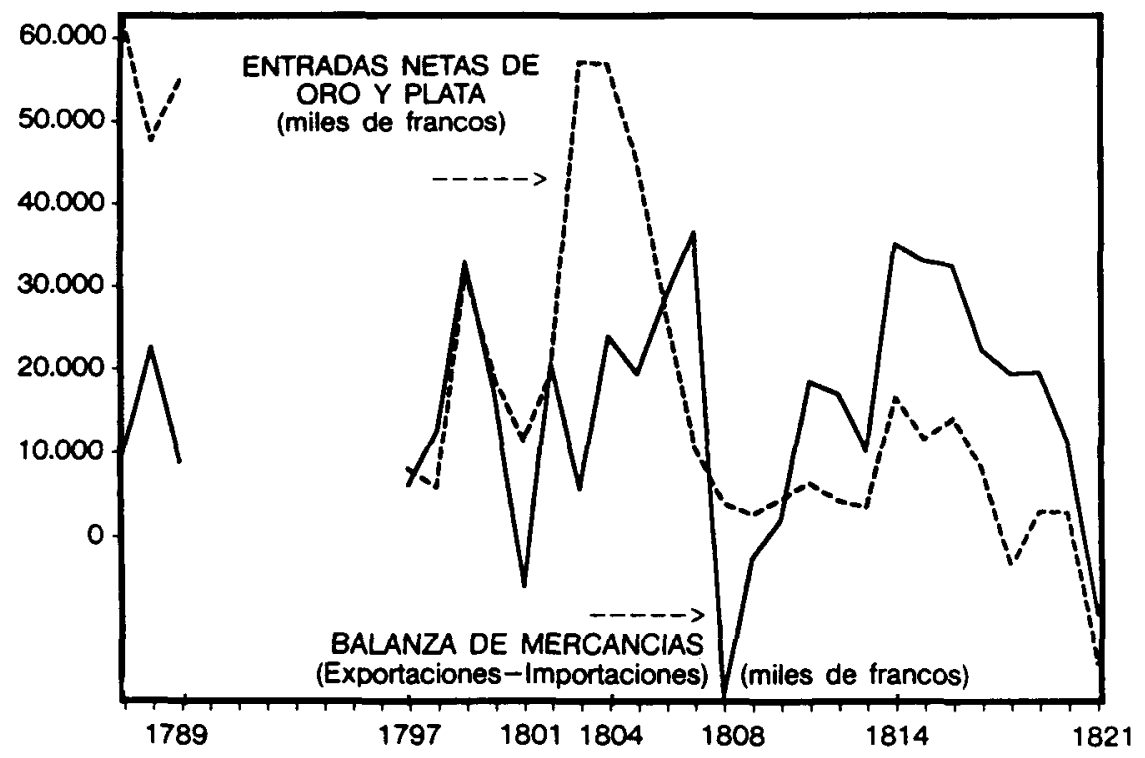

Fuentes: Véase el Apéndice.

La explicación aqui propuesta se apoya, en parte, en las mediaciones de precios y valores comerciales que se recogen en el gráfico 4. La hipótesis de partida postula una relación causal entre la coyuntura de los precios relativos en el comercio de tránsito y el drenaje de divisas españolas. Se observa en el gráfico 4 que el colapso de los precios durante la guerra naval de 1797-1801 afectó exclusivamente al componente español de las importacio- 


\section{GRAFICO 4}

Francia. Comercio con España e Indias
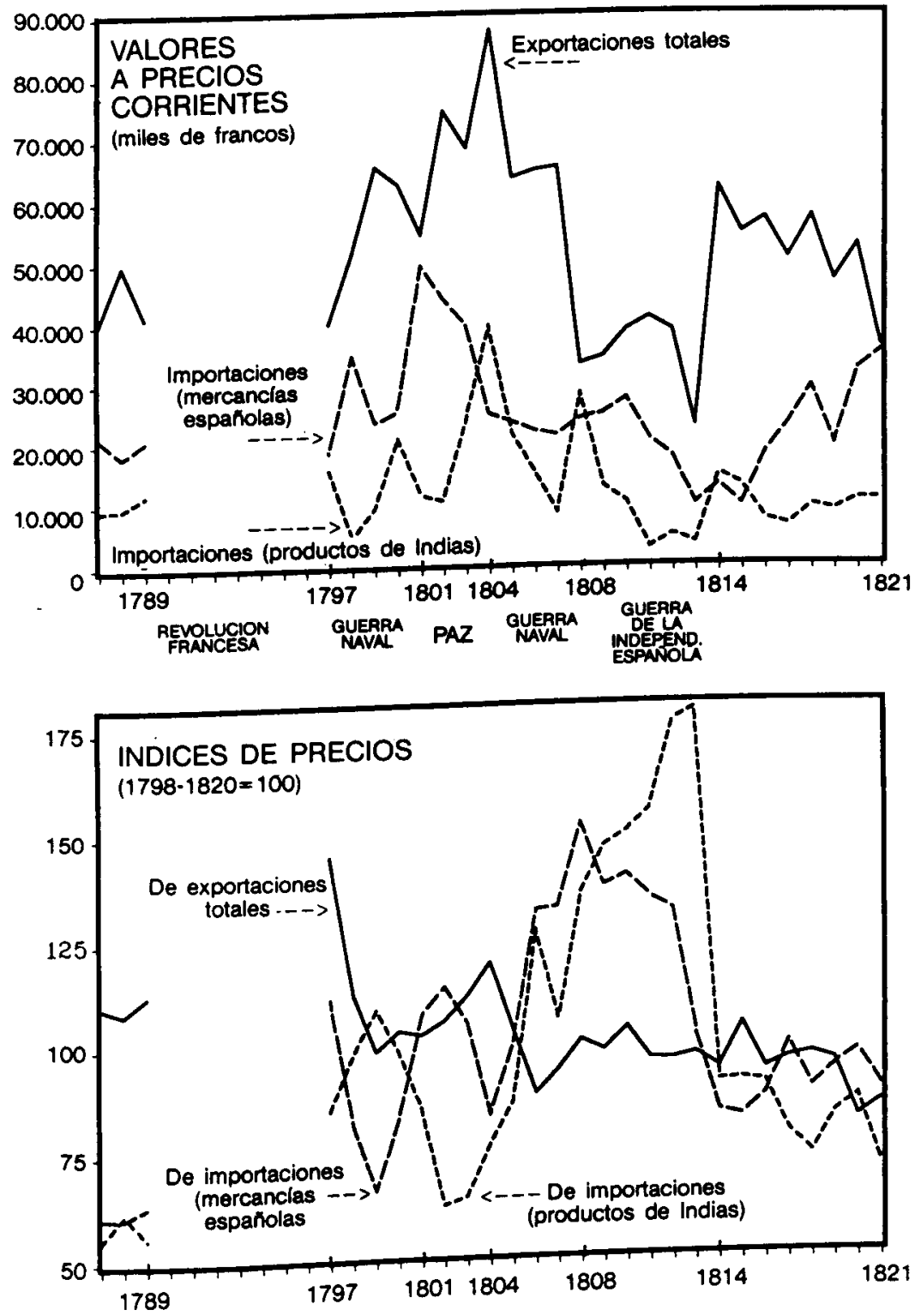

Fuentes y procedimientos de elaboración: Véasc el Apéndice. 
nes francesas (plano inferior) ${ }^{48}$, dándose la circunstancia de que la balanza de mercancías explica plenamente la evolución de las remesas hasta 1800 (cif. gráfico 3) ${ }^{49}$. La ausencia de saldos comerciales descubiertos contra España en estos años de fuertes intercambios de mercancías europeas permitiría excluir a éstos como fuente importante de pérdidas de divisas" ${ }^{50}$. Durante la tregua de Amiens, por el contrario, las exportaciones francesas a España se encarecieron progresivamente al tiempo que se desplomaban los precios de los productos de Indias ${ }^{51}$. De especial relevancia para el presente argumento es la conjunción de estas dos circunstancias en los años 1803 y 1804 con precios descendientes en el mercado francés de mercancías peninsulares, en plena concordancia con los valores máximos del comercio de tránsito (plano superior del gráfico 4) y con las mayores entradas de remesas españolas en Francia.

La peculiar configuración de los precios relativos durante la tregua de Amiens sugiere un segundo vínculo causal con los flujos de dinero por vía indirecta, a través del impacto favorable de la coyuntura sobre el poder de negociación de los comerciantes franceses. Siempre con referencia al gráfi. co 4, se observa en el plano inferior que la evolución de los precios en sentido favorable a Francia en 1802-04 coincidió con una expansión sin precedentes en las exportaciones a España y en las importaciones de productos de Indias (plano superior). Es del todo concebible que la demanda española de manufacturas francesas con destino a las colonias hubiera pujado sus precios al alza muy por encima de las cotizaciones medias que incorporan los valores oficiales, al mismo tiempo que los comerciantes franceses aprovechaban la relativa abundancia de productos de Indias para imponer términos anormalmente favorables en sus compras a España ${ }^{52}$. Es quizá signi-

4* La caída de los precios de exportaciones que recoge el gráfico 4 debe interpretarse con cautela, porque los datos de 1797 son estimaciones basadas en precios ingleses convertidos en francos a tipos de cambio escasamente documentados: véase, a este respecto, J. Cuenca Esteban (1987), pp. 233 y 239-240.

49 Los excedentes de remesas sobre los saldos mercantiles en 1801 podrían explicarse por la llegada de fondos retenidos en América durante las fases más agudas de la guerra naval.

50 No se expresa esta posibilidad en términos categóricos porque las estadísticas oficiales francesas de esta época no distinguen entre las exportaciones francesas a España allí consumidas y las reexportaciones españolas con destino a los mercados coloniales.

\$1 Véase el plano inferior del gráfico 4. La presencia conjunta de precios relativos adversos a España e importantes entradas de remesas españolas en Francia es un rasgo común a las coyunturas de 1787-89 y 1803-05. Desde esta perspectiva, la novedad de la tregua de Amiens radica en la expansión sin precedentes en el comercio de tránsito por la península, especialmente en el ramo de exportaciones francesas a España.

52 Es importante recordar aquí que los precios que se usaron para calcular los valores oficiales franceses de exportaciones e importaciones no fueron necesariamente los realmente pagados, sino medias aritméticas anuales de las cotizaciones de mercado: referencias y análi- 
ficativo en este último sentido que los precios en Cádiz de los principales productos de Indias se mantuvieron en estos años relativamente deprimidos en comparación con los franceses ${ }^{53}$. Los efectos diferenciales de estas fuerzas de mercado sobre los valores reales de exportación e importación explicarían tanto los excedentes de remesas sobre la balanza oficial de mercancías en los años 1803-05 como los déficit de la segunda década del siglo, en condiciones coyunturales estas últimas desfavorables a Francia. Una implicación general de este análisis es que el componente de tránsito del comercio exterior español pudo haber sido deficitario en coyunturas que agudizaban la competencia en los mercados europeos, coincidentes en este caso con los años de mayor apertura del comercio de Indias. En la medida en que las fluctuaciones de precios del período 1797-1805 incorporan determinantes últimos enraizados en la estructura y composición del comercio franco-español, las mismas variables que mediatizaron la coyuntura adversa a España explicarían también el drenaje de divisas españolas durante los años 1803-05.

\section{IV}

El análisis precedente ha puesto de manifiesto que la evolución del comercio exterior español en el período 1797-1807 no fue un mero reflejo de los conflictos bélicos de la época. Las cifras hoy disponibles sugieren que el comercio de tránsito por la península se encontró en estos años ante una coyuntura desfavorable de precios europeos, y que la culminación de las tendencias adversas durante la tregua de Amiens coincidió con un serio drenaje de divisas españolas hacia Francia. La confluencia en estos años de excedentes contra España por cuenta de los precios relativos, especialmente en los importantes intercambios franceses de manufacturas por productos de Indias, apunta al comercio de tránsito franco-español como origen probable de interacciones adversas decisivas. El análisis de los procesos de ajuste en tres submercados franceses ha permitido identificar dos variables clave que vinculan la estructura del comercio con las tendencias desfavorables a España: la elasticidad de la demanda francesa de productos de Indias y el

sis en J. Cuenca Esteban (1987), Pp. 224-231. Este método de cálculo deja un amplio mardos reales en la balanza de mercancías muy distintos a los que arrojan las cifras of iciales.

53 Cif. los precios en Cádiz y en Francia del añil y del azúcar, en J. Cuenca Esteban (1990), pp. 391 y 393. Convertidos en francos con los tipos de cambio internacional ya nados, los precios en Cádiz durante estos años resultan ser muy inferiores a los franceses en unidades comunes. 
grado de apertura del comercio colonial. El hecho central es que Francia exportaba manufacturas indispensables para el comercio de Indias, a cambio de mercancías que, en su mayor parte, tenían sustitutos en el mercado francés y cuya demanda era, por consiguiente, elástica. En años de guerra naval con intervención de buques neutrales (1797-1801), el encarecimiento a corto plazo de los productos de Indias en la península contribuyó a estimular en Francia la sustitución de importaciones por vía no española; al mismo tiempo, la presión de la oferta española de mercancías domésticas sin salida para las colonias deprimía sus precios. Con el retorno de la paz (1802-04) fueron los productos de Indias los que se hallaron en relativa abundancia, y aquí la oferta española de estas mercancías afluyó al mercado francés en proporciones masivas y a precios aún más deprimidos. En ambos casos, la coyuntura internacional hundió los precios de los excedentes cuya exportación era vital para España. Por el lado de las importaciones españolas, la presión de la demanda colonial durante la tregua de Amiens encareció las manufacturas francesas en los años de mayor comercio de tránsito por la península. En la medida en que estas condiciones de mercado pudieron haber reforzado el poder de negociación de los comerciantes franceses, las mismas variables que mediatizaron la coyuntura adversa a España explicarían también el drenaje de divisas españolas durante los años 1803-05. En última instancia, por consiguiente, la debilidad del Imperio en su encrucijada decisiva no habría sido enteramente un fracaso político ni, desde luego, una circunstancia fortuita, sino consecuencia en parte de la estructura y composición del comercio español.

El impacto de la coyuntura española en los mercados coloniales no será fácil de desentrañar, y no sólo por falta de datos. La hipótesis de una posible conexión causal entre los precios europeos y los americanos no es, por supuesto, nueva en la historiografía del período colonial. Ya en 1959 se comprobó una correlación positiva entre las cotizaciones del añil en Amsterdam y en Guatemala desde 1758 hasta $1806^{54}$. Los datos publicados desde entonces permiten ya postular tendencias a largo plazo en los precios de ciertas mercancías coloniales, pero la explicación de estas tendencias y de sus posibles conexiones ultramarinas está todavía en su infancia ${ }^{55}$. Se han buscado factores causales en la demanda europea y en los desplaza-

54 R. S. Smith (1959), p. 205. Smith no corrigió las series de precios con tipos de cambio internacional, ni aventuró hipótesis sobre los mecanismos de transmisión de las fluctuaciones a través del Atlántico.

55 Véanse R. Romano (1990), pp. 42-43; E. Tandeter y A. Wachtel (1983), pp. 88-90, y R. Garner (1990), p. 97. Las dos tendencias a largo plazo durante el siglo xvil habrían sido de sentido inverso: una deflacionaria en Santiago de Chile, Potosí, Arequipa y Río de Janeiro, y otra en México más congruente con los precios ascendientes en Europa y en Norteamérica. 
mientos de oferta debidos al comercio ${ }^{56}$, Pero a nivel de mercancías específicas la importancia relativa de estos mecanismos de transmisión permanece incierta. Robert Ferry no ha encontrado una correlación negativa sistemática entre las exportaciones de cacao de Caracas y los precios de esta mercancía en Veracruz durante la primera mitad del siglo XviII, posiblemente porque Nueva España también recibía cacao de Guayaquil, mientras que el de Caracas se exportaba cada vez más a Cádiz ${ }^{57}$. Eugenio Piñero sí comprobó una relación inversa entre las importaciones españolas de cacao y los precios del chocolate en Madrid en los años 1731-1775, pero aquí la correlación es débil debido en parte a que el cacao se almacenaba en España para evitar descensos bruscos de precios ${ }^{58}$. Estos análisis confirman la importancia del comercio interregional y de las condiciones locales de oferta y demanda a la hora de explicar los precios en Hispanoamérica.

La influencia de Europa en los mercados coloniales durante el período napoleónico se observa con claridad en los raros casos documentados con series idóneas de precios. La hipótesis de que las guerras navales de 1797 1801 y 1804-08 hubieron de abaratar las mercancías exportables en Hispanoamérica se cumple en el caso del añil de Guatemala en 1797-1801, pero no en el de la grana de Nueva España. La clave de esta aparente anomalía en el mercado de la grana parece haber sido la fuerte demanda europea, que contribuyó a mantener los precios locales en línea ascendiente tanto en los años de guerra como en los de paz. Durante la primera guerra naval (1797-1801), el boyante comercio de neutrales por el puerto de Veracruz dio salida a cantidades sin precedentes de grana en 1798-99 a precios muy superiores a los de paz. A impulsar la tendencia ascendiente en las cotizaciones de la grana durante la tregua de Amiens contribuyó después el decreto de Consolidación de 1804, que incidió duramente sobre los fondos disponibles en Nueva España para financiar la producción indígena ${ }^{59}$. Los precios del añil en Guatemala muestran una trayectoria muy distinta, con niveles muy deprimidos en 1797-99 y una mera recuperación de estas pérdidas a partir de la tregua de Amiens ${ }^{60}$. La oferta de añil también se vio reducida por plagas de langosta, escasez de financiación y otras circunstan-

56 Véanse, por ejemplo, R. Garner (1990), p. 97; L. Johnson (1990), p. 162; K. Brown (1990), p. 183; M. Haitín (1985), p. 182, y D. Alden (1990), p. 359.

${ }_{57}$ R. Ferry (1990), pp. 316-318.

5* E. Piñero (1988), pp. 80-81.

s4 Análisis y cifras de precios y producción de graniento como fuente de financiación para 103, 115 y 169-170. Sobre la importancia del pp. 6-7.

la producción indigena, véanse, tambien de precios de tres calidades de añil de $\mathrm{R}$. S. Smith

(195)), Péase, entre otras, la recopilación de precios de $1758-1810$; desgraciadamente, faltan datos para 1804-05.
(195) 
cias a partir de 1802 , pero aquí el factor determinante de la relativa atonía de los precios parece haber sido la sustitución de importaciones en Europa a favor del añil de Bengala por iniciativa inglesa ${ }^{61}$. La importancia de la demanda ultramarina en ambos casos sugiere que todo análisis de las condiciones locales en los puertos americanos de origen habrá de incorporar también los precios en los mercados europeos de destino, así como los costes del transporte marítimo y los derechos de aduanas en cada caso.

Más difícil de valorar es la posible repercusión de la coyuntura económica española en los años 1797-1807 sobre los movimientos americanos de independencia. La presencia de importantes motivaciones económicas en la mayoría de estos movimientos es hoy generalmente aceptada, aunque se vuelve a insistir en mediaciones sociopolíticas e incluso individuales cada vez más complejas ${ }^{62}$. A nivel regional se han detectado factores de descontento tanto en subidas de precios de consumo como en reducciones de precios de producción durante el siglo XVIII ${ }^{63}$, pero siguen siendo escasos los análisis comparados de los procesos políticos resultantes con utilización de los métodos de las ciencias sociales. De especial interés para el historiador económico en este último sentido es un intento de vincular los procesos políticos en cuatro sociedades coloniales durante el período independentista a la elasticidad de la oferta de las principales mercancías de exportación ${ }^{64}$. Las mediaciones aquí postuladas entre precios y cantidades en el comercio de España con Francia y Gran Bretaña apuntan a otro tipo de presiones que pudieron haber incidido indirectamente en las colonias, especialmente sobre la percepción por parte de productores y consumidores de las crecientes ventajas del comercio directo con extranjeros frente al mantenimiento del monopolio español. La contrastación rigurosa de este tipo de hipótesis requerirá, ante todo, ampliar la base de datos, con especial atención a las cotizaciones de las manufacturas textiles en Europa y en los mercados coloniales. Es quizá en esta llamada a la reordenación de prioridades donde la misma perspectiva que ha hecho posible detectar el problema puede sugerir también las vías de su solución.

61 Véanse R. S. Smith (1959), pp. 198, 203-204, 209, y M. L. Wortman (1982), pp. 186. 189. La principal contribución sobre el mercado mundial del añil en esta época sigue siendo D. Alden (1965).

62 Es muy explícita esta tendencia en las obras recientes de B. R. Hamnett, especialmente (1980).

6.3 Análisis y referencias en H. S. Klein y S. L. Engerman (1990), pp. 15-16.

${ }^{\circ 4}$ Véase J. 1. Domínguez (1980), pp. 116-121. 


\section{APENDICE}

\section{FUENTES Y PROCEDIMIENTOS DE ELABORACION DE LAS CIFRAS}

El núcleo central de este trabajo es un análisis conjunto de precios y cantidades en el comercio franco-español (secciones II y III del texto). Se ha utilizado para este propósito una elaboración ya disponible de las estadísticas de la oficina francesa de la Balance du Commerce, que cubren la totalidad del comercio de Francia con veinte naciones y sus colonias en los años 1787-89 y 1797-1821: J. Cuenca Esteban (1987): cuadro 6, series del comercio franco-español. Las series más significativas se reproducen en los gráficos 3 y 4 (sección III del texto) y, en forma de medias aritméticas por subperíodos, en el cuadro 2 de este Apéndice. A partir de la misma fuente oficial francesa se han calculado también, previa deducción de los flujos monetarios, otras subseries relevantes de mercancías coloniales importadas en Francia por vía no española (medias aritméticas en el cuadro 2: "resto del mundo" y Holanda).

Las cifras oficiales de importaciones francesas no dan subtotales de productos de Indias y mercancías españolas. Para los presentes propósitos, se han calculado subtotales de productos de Indias por agregación de valores de las siguientes mercancías: añil, azúcar, cacao, café, cueros, grana, palo de tinte (Bois des Indes), plomo, quina y la mitad del algodón y del tabaco. Por diferir significativamente esta clasificación de la adoptada en J. Cuenca Esteban (1987: cuadro 6), se ofrece una versión completa de la nueva serie en el cuadro 1: 


\section{CUADRO 1}

Comercio de Francia con el Imperio español, 1787-1821.

Importaciones de productos de Indias

(Valores a precios de mercado, en miles de francos)

\begin{tabular}{|c|c|c|c|c|c|c|c|}
\hline \multicolumn{2}{|c|}{ Años* } & \multirow[b]{2}{*}{9.140} & \multicolumn{2}{|r|}{$A \tilde{n} \mathrm{~s}^{*}$} & \multirow[b]{2}{*}{10.190} & Años & \multirow[b]{2}{*}{4.354} \\
\hline 1787 & & & 1802 & & & $1812 \ldots \ldots \ldots$ & \\
\hline 1788 & 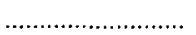 & 9.434 & 1803 & ............... & 23.269 & $1813 \ldots \ldots \ldots \ldots \ldots \ldots \ldots$ & 2.872 \\
\hline \multirow[t]{3}{*}{1789} & . ……… & 11.640 & 1804 & & 39.228 & 1814 & 14.343 \\
\hline & & & 1805 & $\ldots$ & 21.107 & 1815 & 12.255 \\
\hline & & & 1806 & & 14.621 & 1816 & 6.824 \\
\hline 1797 & ……………......... & 15.481 & 1807 & ............................. & 7.949 & $1817 \ldots \ldots \ldots \ldots \ldots \ldots \ldots \ldots \ldots$ & 5.617 \\
\hline 1798 & 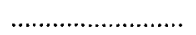 & 4.329 & 1808 & 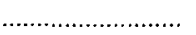 & 27.906 & 1818 & 8.921 \\
\hline 1799 & …………… & 9.212 & 1809 & ․․…………… & 12.187 & 1819 & 8.160 \\
\hline 1800 & …………… & 20.678 & 1810 & 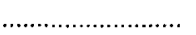 & 9.594 & 1820 & 9.956 \\
\hline 1801 & 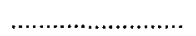 & 11.098 & 1811 & 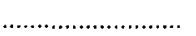 & 2.150 & 1821 & 9.920 \\
\hline
\end{tabular}

* Los valores oficiales de «1797" a "1805" se refieren a años republicanos, que comenzaban hacia el día 22 del septiembre anterior. Los de "1806" abarcan los doce meses de este año y los cien últimos días del anterior.

Para el bosquejo previo de los ciclos y tendencias en el comercio español (sección I) se han utilizado también las conocidas cifras oficiales británicas, que cubren con detalle comparable el comercio con España en los mismos años. Se han recopilado las cantidades importadas de las nueve mercancías más importantes en valor "oficial", con inclusión de todos los cargamentos incautados (prize goods) a que hacen referencia los volúmenes de 1798-1804 en listas separadas: Ledgers of Imports and Exports (Public Record Office, Londres): Customs 17 (vols. 12-30), Customs 4 (vols. 5-7), Customs 14 (Scottish Ledgers: vols. 22-23), Customs 5 (vols. 2-9) y Customs 11 (vols. 1-11): aceite de oliva, aguardiente, algodón (wool cotton), añil, azúcar, brandy, cueros, grana, lana y palo de tinte (logwood). Las cifras de 1809-1811 parecen fragmentarias y, como es sabido, faltan por completo las de 1813. Los valores corrientes de importaciones británicas que se resumen en el cuadro 2 de este Apéndice son el resultado de multiplicar las cantidades anuales de cada mercancía por los precios ingleses respectivos, convertidos estos últimos en francos con los tipos de cambio internacional a que se hace referencia más adelante: precios ingleses mensuales, en A. D. Gayer et al. (1953), passim. Para las exportaciones británicas a España se ha adoptado la reconstrucción de L. Prados de la Escosura (1984), pp. 156-157. 
La riqueza de las estadísticas francesas y británicas ha permitido reconstruir, por agregación de unidades físicas valoradas a precios homologados con tipos de cambio internacional, una aproximación plausible al curso y composición del comercio de España con ambos países en los años 1797. 1821. Los tipos de cambio internacional son los ya presentados en J. Cuenca Esteban (1987), p. 233. Los resultados de este reconstrucción se resumen en los gráficos 1 y 2 (sección I del texto) y en el cuadro 2 de este Apéndice.

Complementan estas cifras comerciales seis índices ponderados de precios franceses e ingleses por grupos de mercancías exportadas e importadas por España, con base en las medias aritméticas respectivas del período 1798-1820. La mayoría de las series individuales de precios son las ya presentadas en J. Cuenca Esteban (1987 y 1990). Los índices de precios de importación son del tipo Paasche; con fines de comprobación se han utilizado otras fuentes españolas y holandesas que se documentan en el texto en los lugares pertinentes. Para las exportaciones británicas a España se ha adoptado el índice de precios del tipo Fisher elaborado por L. Prados de la Escosura (1985), pp. 154-155 (importaciones españolas FOB). Las "Cantidades" o volúmenes de exportación e importación que se resumen en el gráfico 1 y en el cuadro 2 son el resultado de deflactar los valores corrientes en cada caso con los índices de precios respectivos.

Como suplemento de referencia al texto y a los gráficos se resumen a continuación, en el cuadro 2, la mayoría de las cifras utilizadas, en forma de medias aritméticas por subperíodos significativos. Las medias del "Comercio de Francia con España e Indias" en 1797-1808, 1798-1801 y 1802-04 son las que recogen los diagramas I, II y III de la sección II del texto. 


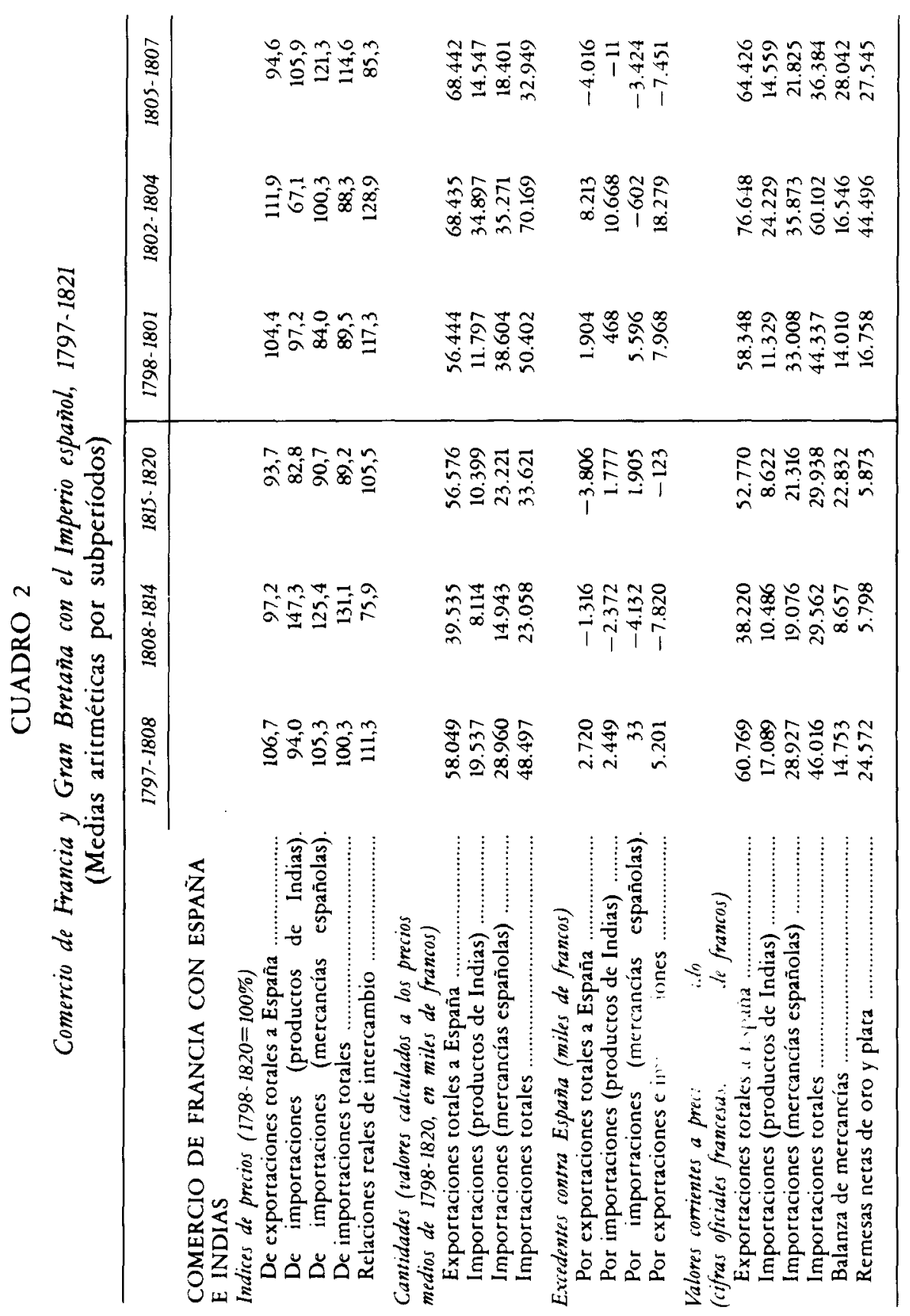




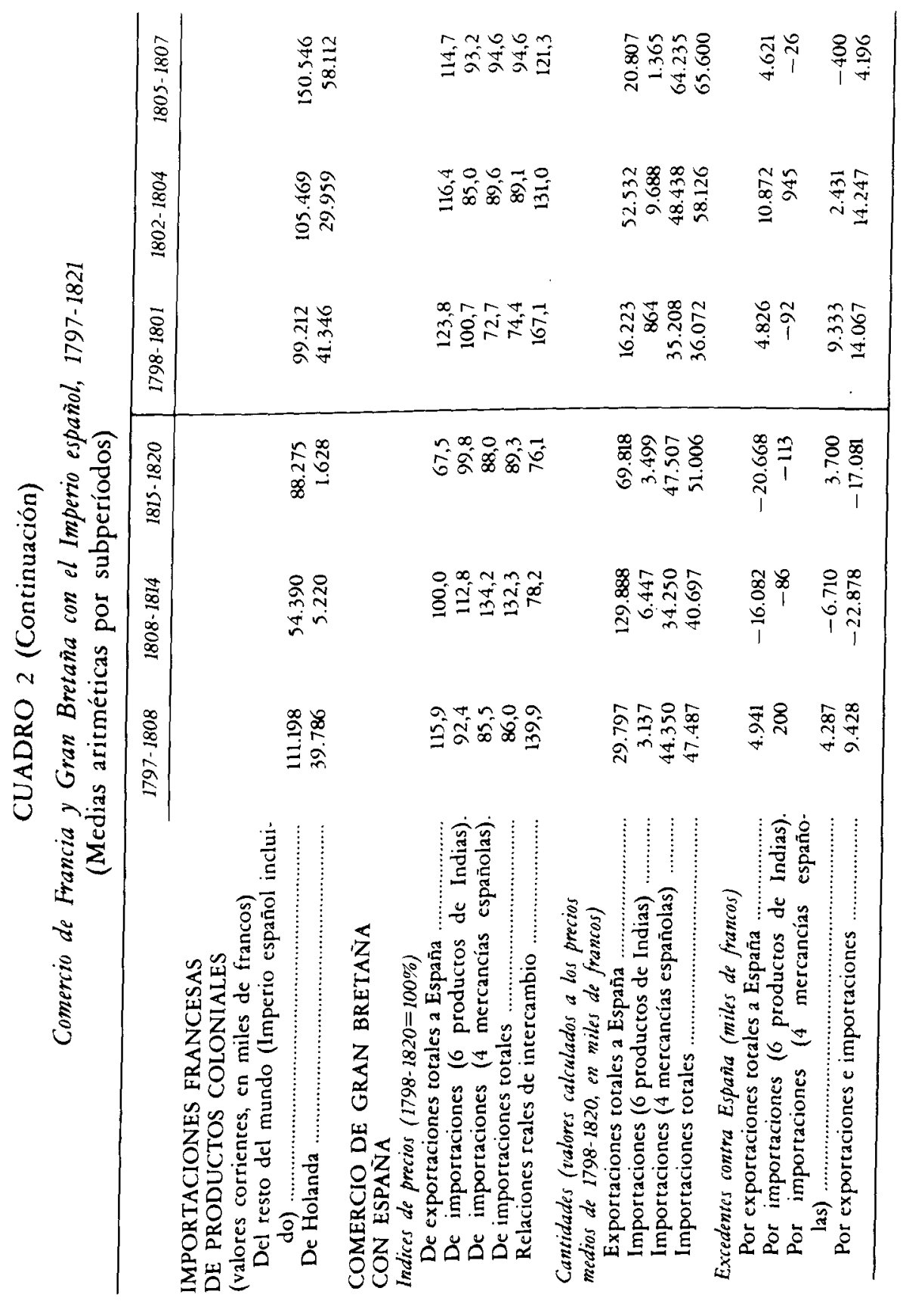




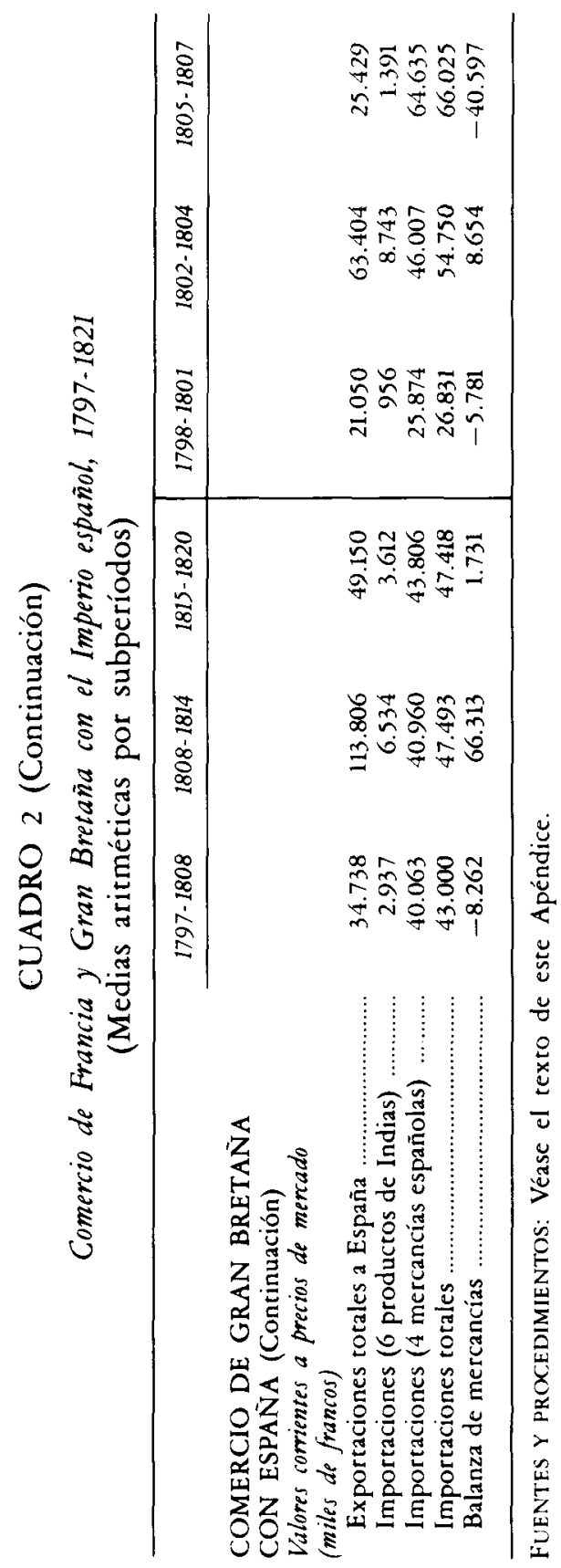




\section{FUENTES Y OBRAS CITADAS}

Alden, Dauril (1965): "The Growth and Decline of Indigo Production in Colonial Brazil: A Comparative Economic History", Joumal of Economic History, 25, núm. 1, pp. 35-60.

- (1990): "Price Movements in Brazil Before, During, and After the Gold Boom, with Special Reference to the Salvador Market, 1670-1769", en Essays on the Price History of Eighteentb-Century Latin America, eds. Lyman L. Johnson y E. Tandeter, Alburquerque: University of New Mexico Press, pp. 335-371.

American State Papers [U. S. Congress] $(1832,1834)$ : Class 4, "Commerce and Navigation". 2 vols., Washington, D. C.: Gales and Seaton.
ANNA, Timothy E. (1983): Spain and the Loss of America, Lincoln: University of Nebraska Press.

Barbier, Jacques A. (1980): "Peninsular Finance and Colonial Trade: The Dilemma of Charles IV's Spain", Joumal of Latin American Studies, vol. 12, parte I (mayo), pp. 21-37.

- (1989): "Comercio neutral in Bolivarian America: La Guaira, Cartagena, Callao and Buenos Aires", en América Latina en la época de Simón Bolívar, ed. R. Liehr (Colloquium Verlag Berlin 1989), Sonderdruck Aus: Bibliotheca Ibero-Americana, pp. 363-377.

Brading, D. A. (1971): Miners and Merchants in Bourbon Mexico, 1763-1810. Cambridge: Cambridge University Press.

Brown, Kendall W. (1990): "Price Movements en Eighteenth-Century Peru: Arequipa", en Essays on the Price History of Eighteenth-Century Latin America, eds. Lyman L. Johnson y E. Tandeter, Alburquerque: University of New Mexico Press, pp. 173-200.

Correo Mercantil de Espana y de sus Indias, Madrid: Imprenta de Vega y Compañía, 1792-1808.

COSTELOE, Michael P. (1886): Response to Revolution. Imperial Spain and the Spanish American Revolutions, 1810-1840. Cambridge: Cambridge University Press.

Cuenca Esteban, Javier (1978): "The Trade and Comercial Policy of Spain, 1765-1826", tesis doctoral, Universidad de Toronto.

- (1981): "Statistics of Spain's Colonial Tic American Historical Review, vol. 61, pp. 381-428. tories, and Balances of Tradew, Hispan la caída del Imperio español, 1778-1826\%, en $\mathrm{La}$

- (1982): "Comercio y Hacienda en la cáda del Comercio y Colonias, ed. J. Fontana, economia española al final del Ania Editorial, pp. 389-453.

Madrid: Banco de España/Alianza Edianterpretión de las estadísticas comerciales francesas

- (1987): "Fundamentos para una inial al comercio franco-español", Hacienda Pública Espade $1787-1821$, con referencia especial

nola, núm. 108/109, pp. 221-251. American Exports, 1790-1820: A Comparative Analysis

- (1990): "The Markets of Latin American Price History of Eighteentb-Century Latin America, of International Pricesm, en Essays on the Price Historye: University of New Mexico Press,
eds. Lyman L. Johnson y E. Tandeter, Alburquerque: pp. $373-399$.

Domingue7, Jorge 1. (1980): Insurrection and Loyaliy. The Breakdoun of the Spanish American Empire. Cambridge, Mass.: Harvard University Press.

Ferry, Robert J. (1990): "The Price of Cacao, its Export, and Rssays on the Price History of Century Caracas: Boom, Bust, and the Byman L. Johnson y E. Tandeter, Alburquerque: Eighteenth-Centring Lersity of New Mexico Press, pp. 309-334.

FonTANA, Josep (1971): La quiebra de la monarquia absoluta, 1814-1820. La crisis del Antigno Régimen en España, Barcelona: Ediciones Ariel.

- (1973): Hacienda y Estado en la crisis final del Antigao Rigimento Instituto de Estudios Fiscales.

- (1987): "La crisis colonial en la crisis del Angua Instituto Nacional de Cultura, 2 vols.. 1780-1840. comp. Alberto Flores Galindo, Lima: I. pp. $17 \cdot 35$. 
García-Baquero González, Antonio (1972): Cometcio colonial y guerras requluctonatias. Sevilla: Escuela de Estudios Hispano-Americanos.

GARNER, Richard L. (1990): "Prices and Wages in Eighteenth-Century Mexico", en Essay's on the Price History of Eigbteenth-Century Latin America, eds. Lyman L. Johnson y E. Tandeter, Alburquerque: University of New Mexico Press, pp. 73-108.

Gayer, Arthur D.; Rostow, W. W., y Schwart7., A. J. (1953): The Grouth and Fluctuation of the British Economy, 1790-1850, 2 vols., Oxford: Clarendon Press, Supplement in Microfilm

Haitín, Marcel (1985): "Prices, the Lima Market, and the Agricultural Crisis of the Late Eighteenth-Century in Colonial Perúm, Jabrbuch für die Gescbicbte ton Staat, Wirtschaft und Gessellschaft Lateinamerikas, 22, pp. 167-198.

HamnetT, Brian R. (1971): Politics and Trade in Southem Mexico, 1750-1821, Cambridge: Cambridge University Press.

- (1986): Roots of Insurgency: Mexican Regions, 1750-1824, Cambridge: Cambridge University Press.

HERR, Richard (1989): Rural Cbange and Royal Finances in Spain at the End of the Old Regime, Berkeley: California University Press.

JoHnson, Lyman L. (1990): "The Price History of Buenos Aires During the Viceregal Period", en Essays on the Price History of Eighteentb-Century Latin America, eds. Lyman L. Johnson y E. Tandeter, Alburquerque: University of New Mexico Press, pp. 137-171.

KLEIN, Herbert, y ENGerman, S. L. (1990): "Methods and Meanings in Price History", en Essays on the Price History of Eighteentb-Century Latin America, eds. Lyman L. Johnson y E. Tandeter, Alburquerque: University of New Mexico Press, pp. 9-20.

Ledgers of Imports and Exports, Public Record Office (Londres): Customs 17 (vols. 12-30), Customs 4 (vols. 5-7), Customs 14 (Scottish Ledgers: vols. 22-23), Customs 5 (vols. 29) y Customs 11 (vols. 1-11).

Libros de Precios Corrientes de la Lonja de Corredores de Cádiz, 1803-1820, AGI (Archivo General de Indias), Consulados, libros 1131 y 1134.

LYNCH, John (1973, 1986): The Spanish-American Revolutions, 1808-1826, Nueva York: W. W. Norton \& Company.

- (1989): Bourbon Spain, 1700-1808, Oxford: Basil Blackwell.

LLOPIS AGELÁN, Enrique (1982): "Las explotaciones trashumantes en el siglo xvill y primer tercio del XIX: La cabaña del Monasterio de Guadalupe, 1709-1835", en La economia espanola al final del Antiguo Régimen. 1. Agricultura. ed. Gonzalo Anes, Madrid: Alianza Edito$\mathrm{rial} /$ Banco de España, pp. 1-101.

MCKInley, P. Michael (1985): Pre-Revolutionary Caracas: Politics, Economy. and Society. Cambridge: Cambridge University Press.

NADAL, Jordi (1975): El fracaso de la Revolución Industrial en España. 1814-1913. Barcelona Ariel.

PIÑERO, Eugenio (1988): "The Cacao Economy of the Eighteenth-Century Province of Caracas and the Spanish Cacao Market", Hispanic American Historical Revieu: 68 , núm. 1 , pp. $75-100$.

PITKIN, Timothy (1835): A Statistical Vieu of the Commerce of the United States of America.... 2.4 ed., New Haven: Durrie \& Peck.

posthumus, Nicolaas Wilhelmus (1946 y 1964): Inquirity into the History of Prices in Holland. 2 vols., Leiden: E. J. Brill.

PRADOS DE LA ESCOSURA, Leandro (1984): "El comercio hispano-británico en los siglos XVIII y Xix. I. Reconstrucción", RFVISTA DE Historia ECONOMICA, año II, núm. 2, pp. 113162.

- (1985): "Las relaciones reales de intercambio entre España y Gran Bretaña durante los siglos XVII1 y XIX", en La nuera Historia Económica en España. eds. P. Martín Aceña y L. Prados de la Escosura, Madrid: Editorial Tecnos, pp. 119-165. 
Romano, Ruggiero (1990): "Some Considerations on the History of Prices in Colonial Latin America, en Essajs on the Price History of Eighteentb-Century Latin America. eds. Lyman L. Johnson y E. Tandeter, Alburquerque: University of New Mexico Press,

Pp. 35-71.
SMITH, Robert S. (1959): "Indigo Production and Trade in Colonial Guatemala", Hispanic American Histonical Revieu: 39, núm. 2, pp. 181-211.

Tableaux Imprimés des Importations et Exportations. ANP (Archives Nationales de Paris), F 12 .

Carton 25l.
TANDETER, E., y WACHTEL, Nathan (1983): Precios y producción agraria. Potosi y Charcas en el siglo XVIII. Buenos Aires: Centro de Estudios de Estado y Sociedad (CEDES).

Wortman, Miles L. (1982): Government and Society in Central America, 1680-1840. Nueva York: Columbia University Press. 